\title{
Thermodynamics of Formation of Porous Polymeric Membrane by Phase Separation Method I. Nucleation and Growth of Nuclei
}

\author{
Kenji Kamide*, Hideki Imsima, and Shigenobu Matsuda \\ Fundamental Research Laboratory of Natural and Synthetic Polymers, \\ Asahi Chemical Industry Co., Ltd., \\ 11-7 Hacchonawate, Takatsuki, Osaka 569, Japan
}

(Received March 1, 1993)

\begin{abstract}
An attempt was made to clarify a general principal describing the steps of nucleation to the growth of the primary particles, based on the thermodynamics of phase equilibrium of mono-dispersed polymer/single solvent systems. Activation energy of formation of critical nucleus $\Delta \phi_{\mathrm{CN}}$ and radius of the critical nucleus $S_{\mathrm{CN}}$ were calculated by using the free energy change due to coagulation per unit volume $\Delta f_{v}$ and interfacial free energy between polymer-rich and -lean phases $\sigma$ on various phase separation points located within the metastable region of phase diagrams. $S_{\mathrm{CN}}$ of critical nucleus generated near a cloud point curve was larger than those near a spinodal curve, but $\Delta \phi_{\mathrm{CN}}$ became smaller when the phase separation occurred near the spinodal curve, indicating that nucleation tends to occur much more easily near the spinodal curve. Nuclei thus formed and passed though a potential barrier are considered to be in equilibrium with the region surrounded by the local solution spheres of polymer-lean phase. The spheres having radii of $S_{0}$ are surrounded by an outer original bulk solution. Growth rate of growing particles were obtained in the isothermal process by solving the general equation of diffusion of polymer molecules from the outer phase. When the phase separation of whole system is attained at time $t_{\mathrm{p}}$, all the nuclei are conventionally defined as the primary particles. By combining the rate of production of critical nuclei and the total volume of $S_{0}$ spheres including growing particles, $t_{\mathrm{P}}$ was determined and distribution of those primary particles was calculated.
\end{abstract}

KEY WORDS Phase Separation / Nucleation / Activation Energy / Interfacial Free Energy / Local Equilibrium / Diffusion / Primary Particle / Porous Polymeric Membrane /

Solvent-casting method is now the most commonly used for preparing the porous polymeric membranes and utilizes the phase separation phenomena of polymer solutions as its basic tenet. The membranes prepared by this method are often composed of the polymer particles as skeleton structure, regardless of their pore sizes. It is clarified by electron micrography (EM) that even reverse osmosis membranes are composed of fine polymer particles. $^{1,2}$

Establishment of underlying principle in the preparation of porous polymeric membranes by the solvent-casting method is unquestionably important in both aspects of science and industry. Kesting, ${ }^{3}$ Smolders, ${ }^{4}$ and Pusch $^{5}$ attempted to give very qualitative explanation for mechanism of formation of unsymmetric membranes.

Kamide et al. made a pioneering work on the relation between the casting conditions and the pore characteristics for cellulose acetate membrane, showing that when cooled down or mixed with poor solvent or solvents mixture

\footnotetext{
* To whom all correspondence should be addressed.
} 
the polymer solution separated into two liquid phases by nucleation mechanism and the trace of the primary particles of polymer-lean phase were detected by EM in the polymer particles constituting dry membranes. ${ }^{6}$ From these, it was demonstrated that the polymer particles constituting the back-bone structure of membranes are the secondary particles, grown from the primary particles in the casting process. Kamide et al. named "Micro-phase separation method" for the method, in which fine polymer-rich phase particles are formed by phase separation of polymer solutions, proposing rather tentative, but quantitative theory for the mechanism of membrane structure formation by solvent-cast method. ${ }^{7}$ In addition, Kamide and his coworkers observed by EM the ultra-thin sections, sliced parallel to the surface of cellulose and cellulose acetate membranes, prepared by the micro-phase separation method, showing that the cellulose and cellulose acetate membranes evidently consist of the small spherical particles having a radius $\left(S_{2}\right)$ of about $0.2 \mu \mathrm{m}$ and the morphology, including pore radius distribution varies continuously with the distance from the membrane surfaces. ${ }^{8}$

In a series of articles, we attempted to establish a more rigorous and generalized theory of thermodynamics on the formation of porous polymeric membranes.

The process of membrane formation can be divided into several elementary steps as shown in Figure 1. Depending on the initial (overall) polymer concentration [i.e., the solution concentration at the instance of phase separation, which should be strictly distinguished from the polymer concentration of the starting (in this case, casting) solution, $v_{\mathrm{p}}^{\mathrm{s}}$ ] $v_{\mathrm{p}}^{0}$, either the polymer-rich phase or the polymer-lean phase will initially separates as the dispersed phase from the solution.

If $v_{\mathrm{p}}^{0}<v_{\mathrm{p}}^{\mathrm{c}}$ (the critical solution concentration), the polymer-rich phase separated as small particles suspended in a medium (i.e., polymerlean phase), and these particles grow by amalgamation. The interstitial space between particles gives pore (non-circular pore) (Figures $1 \mathrm{~b}-1 \mathrm{j})$.

When $v_{\mathrm{p}}^{0}$ is larger than $v_{\mathrm{p}}^{\mathrm{c}}$, the polymer-lean phase is separated as shown in Figures $1 b^{\prime}-1 j^{\prime}$. Since this phase has a comparatively low viscosity, the particles of the polymer-lean phase gradually become larger by amalgamation. The aggregated polymer-lean phase particles are themselves circular, smooth pores. Even in this case, stage $\left(g^{\prime}\right)$ in Figure 1 should be stable in order to prepare the microporous membrane. Figures $1 b^{\prime}-1 j^{\prime}$ strongly suggests that the circular pores will be formed from

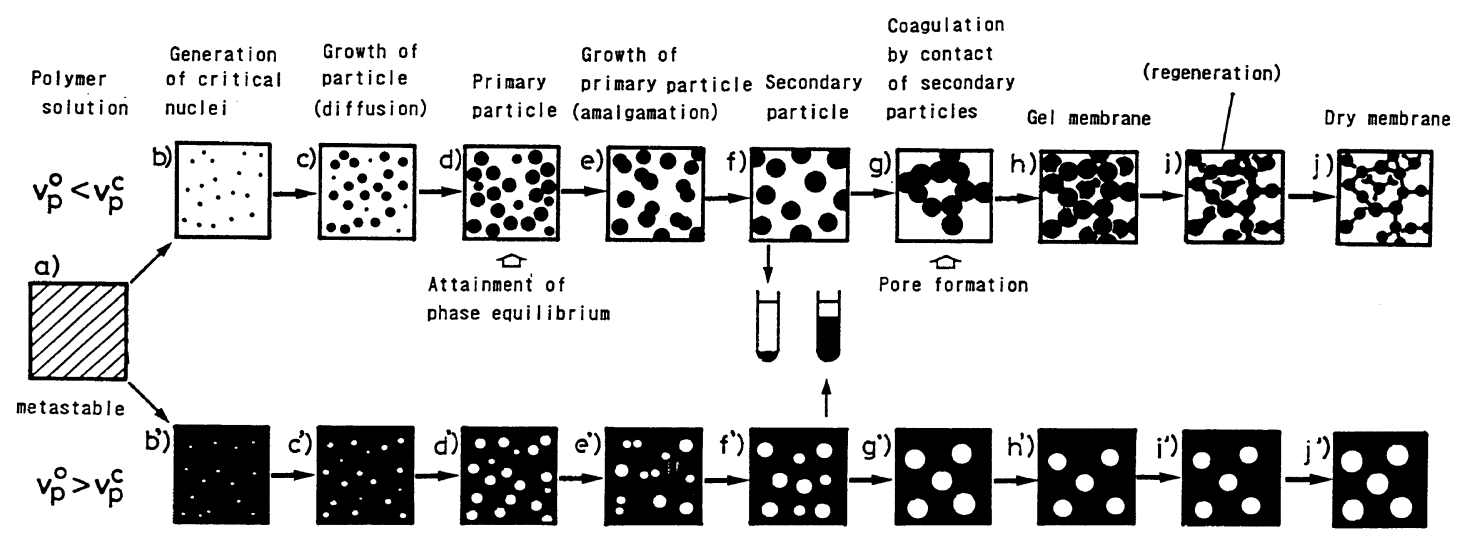

Figure 1. Elementary steps in porous polymeric membrane formation by the micro-phase separation method: $v_{\mathbf{p}}^{0}$, polymer volume fraction of the solution when the phase separation occurs; $v_{\mathbf{p}}^{\mathrm{c}}$, polymer volume fraction of critical solution point. 
concentrated solution.

In this article, we intend to clarify a general principle describing the steps of the nucleation to the growth of the primary particles, based on the thermodynamics of phase equilibrium of multicomponent polymer-solvent system. In other words, we attempted to elucidate (1) the mechanism of nucleation from homogeneous solution, (2) the mechanism of growth from critical nuclei to primary particles, (3) the time at which the phase separation of the whole system is attained, and (4) distribution of radius of the primary particle.

\section{THEORY}

\section{Generation of Critical Nuclei (Step b)}

Before examining the details of the theory, a general explanation of the mechanism of nucleation from the polymer solution will be first presented. The generation and growth of polymer particles (nucleus) by phase separation from homogeneous solution are principally based on the same principle as the condensation of liquid droplets from super-saturated vapors or the formation of ice particles from supercooled liquids: In homogeneous polymer so-

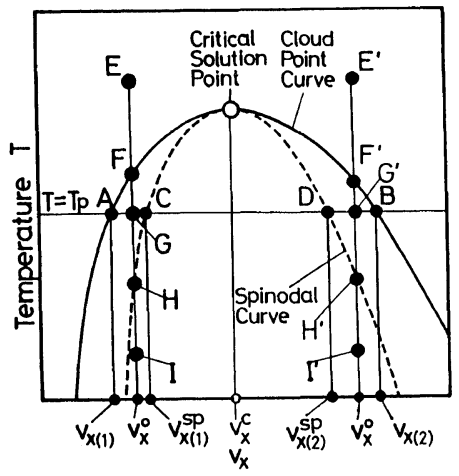

Figure 2. Cloud point curve (solid line), spinodal curve (broken line) and critical solution point (open circle) of monodisperse polymer/solvent system: A and B, coexisting points (at $T=T_{\mathrm{P}} ; T_{\mathrm{\Gamma}}$, phase separation temperature); $\mathrm{C}$ and $\mathrm{D}$, spinodal points $\left(T=T_{\mathrm{P}}\right) ; \mathrm{E}$ and $\mathrm{E}^{\prime}$, one phase points; $F$ and $F^{\prime}$, cloud point; $G$ and $G^{\prime}$, metastable one phase points; $\mathrm{H}$ and $\mathrm{H}^{\prime}$, spinodal points $\left(v=v_{X}^{0}\right)$; $\mathrm{I}$ and $\mathrm{I}^{\prime}$, unstable points. lutions in the metastable region of the phase diagram (points $G$ or $G^{\prime}$ in Figure 2) critical nuclei having radius of $S_{\mathrm{CN}}$ (see, eq 15), are formed by "concentration fluctuation" and can grow further in size spontaneously. The generation of the precipitated nuclei is always time-retarded and the nuclei thus formed grow by passing through a potential barrier (see, Figure 5). On the other hand, under adequate conditions passing through the critical point, the precipitation occurs instantly because of lack in potential barrier: This is spinodal decomposition. ${ }^{9}$

Figure 2 shows the cloud point curve (full line), spinodal curve (broken line), and critical solution point (open circle) for monodisperse polymer $(X$-mer $) /$ single solvent system and Figure 3 shows Gibbs' free energy change $\Delta G_{v}$ per unit volume at a given temperature $T_{\mathrm{P}}$ for $X$-mer/single solvent system. $v_{X(1)}$ and $v_{X(2)}$ are the polymer volume fractions of the polymerlean and -rich phases in equilibrium and $v_{X(1)}^{\mathrm{SP}}$ and $v_{X(2)}^{\mathrm{SP}}$ are spinodal concentrations. In the figure, points $\mathrm{A}$ and $\mathrm{B}$ are two-phase equilibrium points and points $\mathrm{C}$ and $\mathrm{D}$ are spinodal points. If the initial polymer concentration $v_{X}^{0}$ for monodispersed $X$-mer lies at $T_{\mathrm{P}}$ between $v_{X(1)}$ and $v_{X(2)}$, the two-phase separation occurs. When $v_{X}^{0}$ lies between $v_{X(1)}$

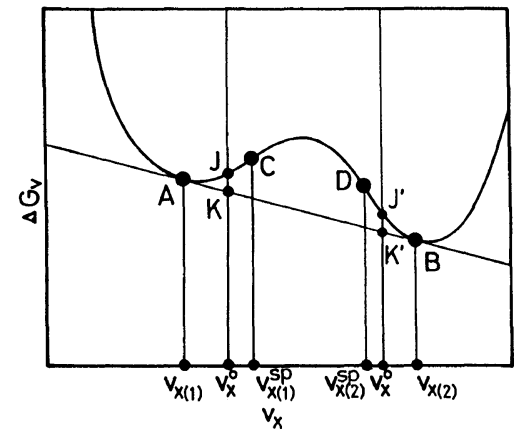

Figure 3. Gibbs' free energy change $\Delta G_{v}$ (eq 3) per unit volume at a given temperature $T_{\mathrm{P}}$ for monodisperse polymer/solvent system: $\mathrm{A}$ and $\mathrm{B}$, coexisting points; $\mathrm{C}$ and $\mathrm{D}$, spinodal points; $\mathrm{J}$ and $\mathrm{J}^{\prime}$, metastable one phase points; $K$ and $K^{\prime}$, points of average free energy of two coexisting phases. 
and $v_{X(1)}^{\mathrm{SP}}$ or between $v_{X(2)}^{\mathrm{SP}}$ and $v_{X(2)}$, the polymer solution can exist as a metastable single phase, from which two-phase separation is initiated by formation of nuclei. In this sense, the spinodal concentration is the upper limit (or lower limit) of concentration, below (or above) which the solution can exist as a metastable single phase for $v_{X}^{0}<v_{X}^{\mathrm{c}}\left(v_{X}^{\mathrm{c}}\right.$, critical polymer volume fraction) (or for $v_{X}^{0}>v_{X}^{\mathrm{c}}$ ). When the polymer solutions at point $E$ (in Figure 2) are cooled down to point $\mathrm{F}$ on cloud point curve, nuclei with a radius of $S_{\mathrm{CN}}$ (see, eq 17) are formed by thermal fluctuation, which can be
a) $v_{p}^{0}<v_{p}^{c}$
b) $v_{p}^{0}>v_{p}^{c}$

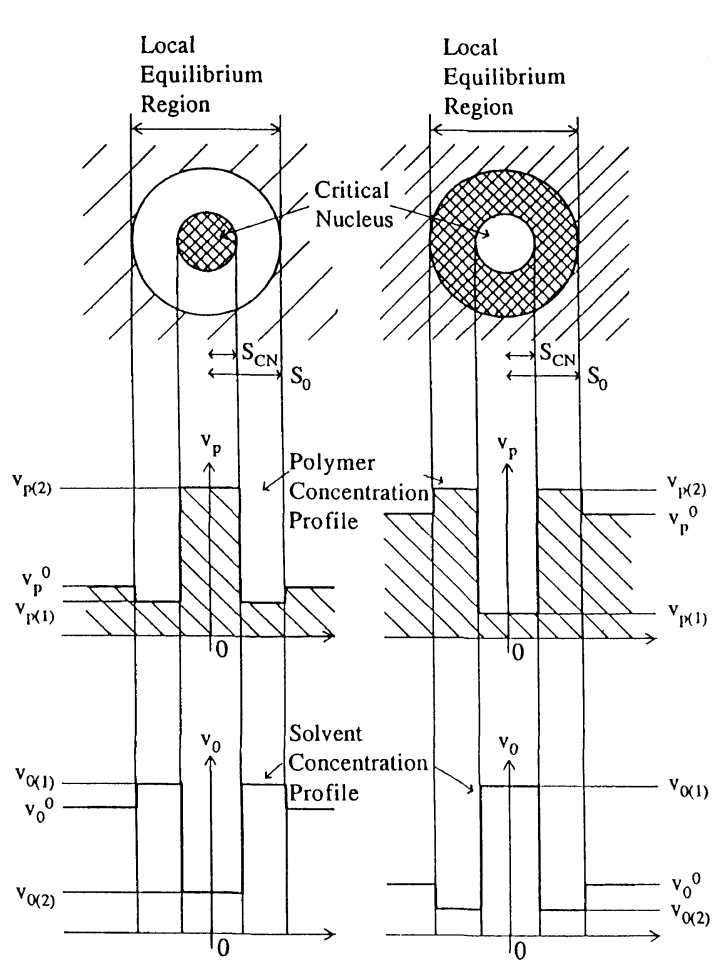

Figure 4. Local equilibrium region and concentration profile of critical nuclei: a) initial (overall) polymer volume fraction of the solution when the phase separation occurs $v_{\mathrm{p}}^{0}<$ polymer volume fraction of critical solution point $v_{\mathrm{p}}^{\mathrm{c}}$, b) $v_{\mathrm{p}}^{0}>v_{\mathrm{p}}^{\mathrm{c}} ; v_{\mathrm{p}(1)}$ and $v_{\mathrm{p}(2)}$; polymer volume fractions of polymer-lean and -rich phases; $v_{0(1)}$ and $v_{0(2)}$, solvent volume fractions of polymer-lean and -rich phases $\left(v_{0(1)}=1-v_{\mathrm{p}(1)}\right.$ and $\left.v_{0(2)}=1-v_{\mathrm{p}(2)}\right) ; S_{\mathrm{CN}}$, radius of critical nucleus; $S_{0}$, radius of local equilibrium region. regarded as concentration fluctuation only and a nucleus thus formed is considered to be in equilibrium with the region immediately surrounded by the local solution (polymer-lean phase), which can be approximated as a sphere with a radius of $S_{0}$ (see, eq $11 \mathrm{c}$ ). In the case of $v_{X}^{0}>v_{X}^{\mathrm{c}}$, the critical nucleus with the radius of $S_{\mathrm{CN}}$ generates according to cooling the polymer solution from point $\mathrm{E}^{\prime}$ to point $\mathrm{F}^{\prime}$ and is surrounded by the region of a sphere $S_{0}$, mentioned above. Figures $4 \mathrm{a}$ and $4 \mathrm{~b}$ show local equilibrium region and concentration profile of critical nuclei in the case of $v_{X}^{0}<v_{X}^{\mathrm{c}}$ and $v_{X}^{0}>v_{X}^{\mathrm{c}}$, respectively. Here, $v_{0}^{0}\left(=1-v_{X}^{0}\right)$ is the initial concentration of the solvent and $v_{0(1)}$ $\left(=1-v_{X(1)}\right)$ and $v_{0(2)}\left(=1-v_{X(2)}\right)$ are the solvent volume fractions of polymer-lean and -rich phases, respectively. The extent of nucleation depends strongly on the time period spent between points $\mathrm{F}$ and $\mathrm{H}$ (or $\mathrm{F}^{\prime}$ and $\mathrm{H}^{\prime}$ ). $\mathrm{H}$ and $\mathrm{H}^{\prime}$ are the points on the spinodal curve. For a given polymer solution, cloud point curve, the spinodal curve and critical solution point can be unambiguously calculated..$^{10-13}$

Consider first the isothermal process. The activation energy of formation of a nucleus with the radius $S, \Delta \phi(S)$ is expressed in the same form as derived for nucleation from polymer melt ${ }^{14}$ :

$$
\Delta \phi(S)=\frac{4}{3} \pi S^{3} \Delta f_{v}+4 \pi S^{2} \sigma
$$

where $\Delta f_{v}$ is the free energy change of coagulation per unit volume, and is defined as the difference between average Gibbs' free energy of coexisting phases $\mathrm{A}$ and $\mathrm{B}, \Delta \bar{G}\left(v_{X}^{0}\right)$ (points $K$ or $K^{\prime}$ in Figure 3) and Gibbs' free energy change of mixing per unit volume $\Delta G_{v}\left(v_{X}^{0}\right)$ (points $\mathrm{J}$ or $\mathrm{J}^{\prime}$ in Figure 3; metastable phase), given by

$$
\Delta f_{v}=\Delta \bar{G}\left(v_{X}^{0}\right)-\Delta G_{v}\left(v_{X}^{0}\right)
$$

and $\sigma$ is the interfacial energy between the nucleus and its surroundings. $\Delta G_{v}$ for single phase (e.g., points $\mathrm{A}, \mathrm{B}, \mathrm{C}, \mathrm{D}, \mathrm{J}$, and $\mathrm{J}^{\prime}$ in Figure 3 ) of monodisperse polymer/single 
Formation of Porous Polymeric Membrane I.

solvent system is

$$
\begin{aligned}
\Delta G_{v}= & v_{0} \frac{\Delta \mu_{0}}{V_{0}}+v_{X} \frac{\Delta \mu_{X}}{X V_{0}} \\
= & \left(\frac{\tilde{R} T}{V_{0}}\right)\left[\left(1-v_{X}\right) \ln \left(1-v_{X}\right)+\frac{v_{X} \ln v_{X}}{X}\right. \\
& +\chi_{0}\left\{\left(v_{X}-v_{X}^{2}\right)+\frac{p_{1}}{2}\left(v_{X}-v_{X}^{3}\right)\right. \\
& \left.\left.+\frac{p_{2}}{3}\left(v_{X}-v_{X}^{4}\right)\right\}\right]
\end{aligned}
$$

where $\Delta \mu_{0}$ and $\Delta \mu_{X}$ are the modified FloryHuggins type chemical potentials of solvent and polymer (i.e., $X$-mer),${ }^{10-13}$ given by the following equations, respectively,

$$
\begin{aligned}
\Delta \mu_{0}= & \tilde{R} T\left[\ln v_{0}+\left(1-\frac{1}{X}\right) v_{X}\right. \\
& \left.+\chi_{0}\left(1+p_{1} v_{X}+p_{2} v_{X}^{2}\right) v_{X}^{2}\right] \\
\Delta \mu_{X}= & \tilde{R} T\left[\ln v_{X}-(X-1)\left(1-v_{X}\right)\right. \\
& +X \chi_{0}\left(1-v_{X}\right)^{2}\left\{1+\frac{p_{1}}{2}\left(1+2 v_{X}\right)\right. \\
& \left.\left.+\frac{p_{2}}{3}\left(1+2 v_{X}+3 v_{X}^{2}\right)\right\}\right]
\end{aligned}
$$

and $V_{0}$ is the molar volume of solvent, $\tilde{R}$, the gas constant, $T$, Kelvin temperature, $\chi_{0}$, the polymer-solvent interaction parameter at infinite dilution, $p_{1}$ and $p_{2}$, 1st and 2 nd order concentration-dependence parameters of thermodynamic interaction parameter between solvent and polymer, $\chi{ }^{10-13} \chi$ is given by

$$
\chi=\chi_{0}\left(1+p_{1} v_{X}+p_{2} v_{X}^{2}\right) .
$$

The coordinates of the points $\mathrm{A}$ and $\mathrm{B}\left[\left(v_{X(1)}\right)\right.$, $\left.\Delta G_{v}\left(v_{X(1)}\right)\right)$ and $\left.\left(v_{X(2)}, \Delta G_{v}\left(v_{X(2)}\right)\right)\right]$ are determined first by applying eq 4 and 5 into the Gibbs' conditions for two-phase equilibrium eq 7 and 8 , respectively, ${ }^{10-13}$

$$
\Delta \mu_{0(1)}=\Delta \mu_{0(2)}
$$

$$
\Delta \mu_{X(1)}=\Delta \mu_{X(2)}
$$

and by substituting $v_{X(1)}$ and $v_{X(2)}$ thus calculated into eq 3 .

$\Delta \bar{G}\left(v_{X}^{0}\right)$ at point $K\left(v_{X}^{0}, \Delta \bar{G}\left(v_{X}^{0}\right)\right)$ is given by the relation,

$$
\begin{aligned}
\Delta \bar{G}\left(v_{X}^{0}\right)= & \frac{\Delta G_{v}\left(v_{X(2)}\right)-\Delta G_{v}\left(v_{X(1)}\right)}{v_{X(2)}-v_{X(1)}}\left(v_{X}^{0}-v_{X(1)}\right) \\
& +\Delta G_{v}\left(v_{X(1)}\right) .
\end{aligned}
$$

Then, substituting eq 3 and 9 into eq $2, \Delta f_{v}$ can be straightforwardly calculated.

Of course, between the phase volume ratio $R, v_{X}^{0}, v_{X(1)}$, and $v_{X(2)}$ the relation

$$
R \equiv \frac{V_{(1)}}{V_{(2)}}=\frac{v_{X(2)}-v_{X}^{0}}{v_{X}^{0}-v_{X(1)}}
$$

holds. Here, $V_{(1)}$ and $V_{(2)}$ are the volumes of the polymer-lean and -rich phases, respectively. We adopt the hypothesis that thermodynamic equilibrium is attained between the nucleus $\left(0<S<S_{\mathrm{CN}}\right)$ and its surrounding sphere $\left(S_{\mathrm{CN}}<S<S_{0} ; S_{0}\right.$, radius of local equilibrium region), but there is no equilibrium between the sphere and its outer large homogeneous phase $\left(S>S_{0}\right)$ (Figure 4). However, note that this hypothesis (i.e., "local equilibrium hypothesis") has not yet been fully verified experimentally. When "local equilibrium hypothesis" is accepted, $V_{(1)}, V_{(2)}$, and $R$ are given by the formula:

In the case of $v_{X}^{0}<v_{\mathbf{X}}^{\mathrm{c}}$

$$
\begin{aligned}
& V_{(1)}=\frac{4}{3} \pi\left(S_{0}^{3}-S_{\mathrm{CN}}^{3}\right), \\
& V_{(2)}=\frac{4}{3} \pi S_{\mathrm{CN}}^{3}, \\
& R=\frac{S_{0}^{3}-S_{\mathrm{CN}}^{3}}{S_{\mathrm{CN}}^{3}} .
\end{aligned}
$$

In the case of $v_{X}^{0}>v_{X}^{\mathrm{c}}$

$$
V_{(1)}=\frac{4}{3} \pi S_{\mathrm{CN}}^{3},
$$




$$
\begin{aligned}
& V_{(2)}=\frac{4}{3} \pi\left(S_{0}^{3}-S_{\mathrm{CN}}^{3}\right), \\
& R=\frac{S_{\mathrm{CN}}^{3}}{S_{0}^{3}-S_{\mathrm{CN}}^{3}} .
\end{aligned}
$$

Coordinates of the spinodal points $\mathrm{C}$ and $\mathrm{D}$ $\left[\left(v_{X(1)}^{\mathrm{SP}}, \Delta G_{v}\left(v_{X(1)}^{\mathrm{SP}}\right)\right)\right.$ and $\left.\left(v_{X(2)}^{\mathrm{SP}}, \Delta G_{v}\left(v_{X(2)}^{\mathrm{SP}}\right)\right)\right]$ can be calculated by solving the equation ${ }^{13}$

$$
\frac{1}{1-v_{X}}+\frac{1}{X v_{X}}-\chi_{0}\left(2+3 p_{1} v_{X}+4 p_{2} v_{X}^{2}\right)=0
$$

for a given $\chi_{0}$. And the critical solution point $\left(v_{X}^{\mathrm{c}}, \chi_{0}^{\mathrm{c}}\right)$ can be evaluated by solving the simultaneous equations (eq 13 and 14). ${ }^{13}$

$$
\frac{1}{\left(1-v_{X}\right)^{2}}-\frac{1}{X v_{X}^{2}}-\chi_{0}\left(3 p_{1}+8 p_{2} v_{X}\right)=0 .
$$

The above discussion on monodisperse polymer/solvent system can easily be extended to more general systems including polydisperse polymer/solvent/nonsolvent system.

Evidently, $\Delta \phi$ is a function of $S$ as illustrated in Figure $5 . \Delta \phi$ of Figure 5 is calculated using $\Delta f_{v}=-300.99 \mathrm{~J} \mathrm{~m}^{-3}$ and $\sigma=3 \times 10^{-6} \mathrm{~J} \mathrm{~m}^{-2}$. The radius of critical nuclei, $S_{\mathrm{CN}}$ is derived by applying the condition of $\partial \Delta \phi / \partial S=0$ to eq 1 to yield

$$
S_{\mathrm{CN}}=-\frac{2 \sigma}{\Delta f_{v}}
$$

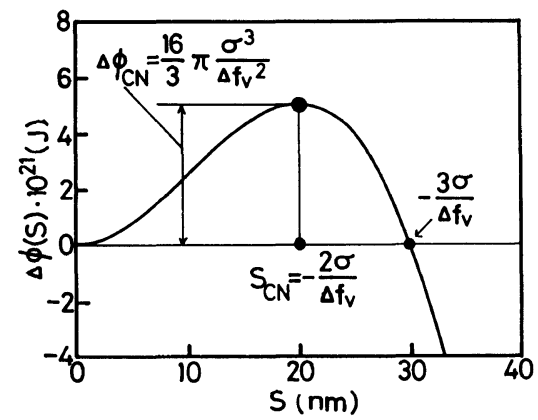

Figure 5. Plot of activation energy of formation of nucleus $\Delta \phi(S)$ as a function of nucleus size $S$ (eq 1): $\Delta f_{v}=-300.99 \mathrm{~J} \mathrm{~m}^{-3} ; \sigma=3 \times 10^{-6} \mathrm{~J} \mathrm{~m}^{-2} ;$ in this case, $S_{\mathrm{CN}} \approx 20 \mathrm{~nm}$ and $\Delta \phi_{\mathrm{CN}} \approx 5 \times 10^{-21} \mathrm{~J}$.
When a nucleus formed at a given instant has a radius $S_{\mathrm{N}}$ larger than $S_{\mathrm{CN}}$, the nucleus will continue to grow spontaneously. The activation energy of formation of critical nucleus $\Delta \phi_{\mathrm{CN}}$ is written by combining eq 15 with eq 1 as

$$
\Delta \phi_{\mathrm{CN}}=\frac{16 \pi \sigma^{3}}{3 \Delta f_{v}^{2}} .
$$

It should be emphasized that in this case, although the phase equilibrium has not yet been attained over the whole solution system, $R$ for the local equilibrium region surrounding each nucleus is considered to coincide with $R$ for the whole system (eq 10).

\section{Growth of Nucleus (Step c) to Primary Particle (Step d)}

The profile of polymer concentration around a nucleus $\left(v_{\mathbf{p}}^{0}<v_{\mathbf{p}}^{\mathrm{c}}\right)$ is demonstrated in Figure 6. Then, the polymer concentrations of a nucleus, its surrounding sphere and outer homogeneous phase are $v_{\mathbf{p}(1)}, v_{\mathbf{p}(2)}$, and $v_{\mathbf{p}}^{0}$, respectively. $S_{0}$ is related to $R$ through the relation:

$$
\begin{array}{ll}
R=\frac{S_{0}^{3}-S_{\mathrm{CN}}^{3}}{S_{\mathrm{CN}}^{3}}\left(=\frac{v_{\mathrm{p}(2)}-v_{\mathrm{p}}^{0}}{v_{\mathrm{p}}^{0}-v_{\mathrm{p}(1)}}\right) & \text { for } \quad v_{\mathrm{p}}^{0}<v_{\mathrm{p}}^{\mathrm{c}} \\
R=\frac{S_{\mathrm{CN}}^{3}}{S_{0}^{3}-S_{\mathrm{CN}}^{3}}\left(=\frac{v_{\mathrm{p}(2)}-v_{\mathrm{p}}^{0}}{v_{\mathrm{p}}^{0}-v_{\mathrm{p}(1)}}\right) & \text { for } \quad v_{\mathrm{p}}^{0}>v_{\mathrm{p}}^{\mathrm{c}}
\end{array}
$$

Of course, $v_{\mathrm{p}(1)}$ and $v_{\mathrm{p}(2)}$ can be calculated theoretically for any polymer solution.

For $v_{\mathrm{p}}^{0}<v_{\mathrm{p}}^{\mathrm{c}}$, after the generation of a nucleus, the polymer molecules in the outer phase, based on the concentration difference $v_{\mathrm{p}}^{0}-v_{\mathrm{p}(1)}$, immediately diffuse into the sphere (Figure 6b). The number of the polymer molecules diffusing through the unit area of the spherical surface from the outer phase per unit time is given by solving the general equation of diffusion in the form

$$
\frac{\partial v_{\mathrm{p}}}{\partial t}=D \nabla^{2} v_{\mathrm{p}}
$$




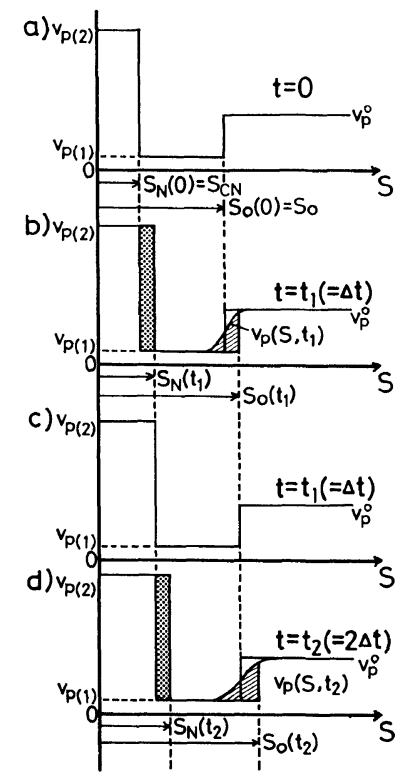

Figure 6. Concentration profiles of a critical nucleus with a radius of $S_{\mathrm{N}}(t)$ and its surrounding sphere with a radius of $S_{0}(t)$ : a) the profile of polymer concentration around the critical nucleus at $t=0 . v_{\mathrm{p}(2)}$, the polymer concentration of nucleus, $v_{\mathrm{p}(1)}$, its surrounding sphere and $v_{\mathrm{p}}^{0}$, its outer homogeneous phase; $b$ ) increase of the radius of the nucleus (shadowed area) due to diffusion $\left[v_{\mathrm{p}}\left(S, t_{1}\right)\right.$, hatched area] from the outer phase at $t=t_{1}(=\Delta t)$; c) the profile of polymer concentration around the nucleus at $t=t_{1} ; \mathrm{d}$ ) increase of the radius of the nucleus (shadowed area) due to diffusion $\left[v_{\mathrm{p}}\left(S, t_{2}\right)\right.$, hatched area] from the outer phase at $t=t_{2}(=2 \Delta t)$.

with

$$
\begin{aligned}
\nabla^{2} & =\frac{1}{S^{2}} \frac{\partial}{\partial S}\left(S^{2} \frac{\partial}{\partial S}\right) \\
& +\frac{1}{S^{2}}\left\{\frac{1}{\sin \theta} \frac{\theta}{\partial \theta}\left(\sin \theta \frac{\partial}{\partial \theta}\right)+\frac{1}{\sin ^{2} \theta} \frac{\partial^{2}}{\partial \psi^{2}}\right\}
\end{aligned}
$$

( $\theta$ and $\psi$ are polar coordinates) under the boundary conditions of $v_{\mathrm{p}}(S, 0)=v_{\mathrm{p}(1)}$ in the range of $S_{\mathrm{CN}}<S<S_{0}(0)$ and $v_{\mathrm{p}}(S, 0)=v_{\mathrm{p}}^{0}$ for $S_{\mathrm{CN}}>S_{0}(0)$ (Figure 6a) as ${ }^{15}$

$$
v_{\mathbf{p}}(S, t)=\left(v_{\mathbf{p}}^{0}-v_{\mathbf{p}(1)}\right)\left[\frac{\phi\left(S_{0+}\right)+\phi\left(S_{0-}\right)}{2}\right.
$$

$$
\begin{aligned}
& +\frac{1}{S} \sqrt{\frac{D t}{\pi}}\left\{\exp \left(-S_{0+}^{2}\right)\right. \\
& \left.\left.-\exp \left(-S_{0-}^{2}\right)\right\}\right]+v_{\mathrm{p}(1)}
\end{aligned}
$$

where

$$
\begin{aligned}
& \phi(x)=\frac{2}{\sqrt{\pi}} \int_{0}^{x} \exp \left(-u^{2}\right) \mathrm{d} u, \\
& S_{0+}=\frac{S_{0}+S}{2 \sqrt{D t}}, \\
& S_{0-}=\frac{S_{0}-S}{2 \sqrt{D t}} .
\end{aligned}
$$

Here, $\phi(x)$ is the error function, $D$, the diffusion coefficient and $t$, the growing time of nucleus by diffusion. We define $t=0$ as the instant of appearance of a critical nucleus and the concentration profile around the nucleus at $t=t_{1}(=\Delta t)$ is illustrated in Figure 6b. If we can also assume that the thermodynamic equilibrium holds even at $t=t_{1}$ between the nucleus $\left(0<S<S_{\mathrm{N}}\left(t_{1}\right)\right)$ and the surrounding sphere $\left(S_{\mathrm{N}}\left(t_{1}\right)<S<S_{0}\left(t_{1}\right)\right)$, the diffusion of polymer molecules (hatched area in Figure 6b) from the outer phase into $S_{0}(0)$ sphere will instantly result in an increase in the radius of the nucleus (shadowed area in Figure $6 \mathrm{~b}$ ) yielding $S_{\mathrm{N}}\left(t_{1}\right)$ [i.e., $S_{\mathrm{CN}}\left(\equiv S_{\mathrm{N}}(0)\right) \rightarrow S_{\mathrm{N}}\left(t_{1}\right)$ ] (see, Figure 6b). This can be understood as nucleus growth. When the thermodynamic equilibrium between the nucleus and its surrounding sphere holds even at $t=t_{2}(\equiv 2 \Delta t)$, the radius of the nucleus increases from $S_{\mathrm{N}}\left(t_{1}\right)$ to $S_{\mathrm{N}}\left(t_{2}\right)$ (Figures $6 \mathrm{c}$ and $6 \mathrm{~d}$ ). The concentration profile of diffusion at $t=t_{2}, v_{\mathrm{p}}\left(S, t_{2}\right)$ can be numerically evaluated in this case by solving the diffusion equation (eq 19) under the boundary conditions of $v_{\mathrm{p}}\left(S, t_{1}\right)=v_{\mathrm{p}(1)}\left(S_{\mathrm{N}}\left(t_{1}\right)<S<\right.$ $\left.S_{0}\left(t_{1}\right)\right)$ and $v_{\mathrm{p}}\left(S, t_{1}\right)=v_{\mathrm{p}}^{0}\left(S>S\left(t_{1}\right)\right)$.

The above treatment can be readily extended to the more general case of a nucleus with a radius of $S_{\mathrm{N}}\left(t_{1}\right)$ and its surrounding sphere with a radius of $S_{0}\left(t_{1}\right)$, obtained at time $t=t_{i}(\equiv i \Delta t)$. 
$v_{\mathrm{p}}\left(S, t_{1}\right)$ can be estimated by solving eq 19 under the boundary conditions of $v_{\mathrm{p}}\left(S, t_{i-1}\right)=v_{\mathrm{p}(1)}$ $\left(S_{\mathrm{N}}\left(t_{i-1}\right)<S<S_{0}\left(t_{i-1}\right)\right)$ and $v_{\mathrm{p}}\left(S, t_{i-1}\right)=v_{\mathrm{p}}^{0}$ $\left(S>S_{0}\left(t_{i-1}\right)\right)$ when the following relation holds

$$
R=\frac{S_{0}\left(t_{i}\right)^{3}-S_{\mathrm{N}}\left(t_{i}\right)^{3}}{S_{\mathrm{N}}\left(t_{i}\right)^{3}} \quad(i=1,2,3, \cdots)
$$

among $S_{\mathrm{N}}\left(t_{i}\right), S_{0}\left(t_{i}\right)$ and the phase volume ratio $R$ determined by eq 17 .

An increment of polymer volume during $t=t_{i-1}$ and $t=t_{i}$ in the polymer-lean phase ranging from $S_{\mathrm{N}}\left(t_{i-1}\right)$ and $S_{0}\left(t_{i}\right), \Delta V_{\mathrm{p}(1)}$ is given by the following equation;

$$
\Delta V_{\mathrm{p}(1)}\left(t_{i}\right)=4 \pi \int_{S_{\mathrm{N}}\left(t_{i-1}\right)}^{S_{0}\left(t_{i}\right)}\left\{v_{\mathrm{p}}\left(S, t_{i}\right)-v_{\mathrm{p}(1)}\right\} S^{2} \mathrm{~d} S .
$$

As the thermodynamics equilibrium is maintained between the nucleus $\left(0<S<S_{\mathrm{N}}\left(t_{i}\right)\right)$ and its surrounding sphere $\left(S_{\mathrm{N}}\left(t_{i}\right)<S<S_{0}\left(t_{i}\right)\right)$ (in other words, eq 7 and 8 hold), polymer concentration of nucleus and its surrounding sphere should be kept as $v_{\mathrm{p}(2)}$ and $v_{\mathrm{p}(1)}$, respectively, and increment of the polymer volume in the polymer-rich phase during $t=t_{i-1}$ and $t=t_{i},\left|\Delta V_{\mathrm{p}(2)}\left(t_{i}\right)\right|$ is the same as $\left|\Delta V_{\mathrm{p}(1)}\left(t_{i}\right)\right|$ under the condition given by eq 24 . Here, $\Delta V_{\mathbf{p}(2)}\left(t_{i}\right)$ is given by

$$
\Delta V_{\mathrm{p}(2)}\left(t_{i}\right)=\frac{4 \pi}{3} v_{\mathrm{p}(2)}\left\{S_{\mathrm{N}}\left(t_{i}\right)^{3}-S_{\mathrm{N}}\left(t_{i-1}\right)^{3}\right\}
$$

and combining eq 25 and 26, we obtain

$$
\begin{aligned}
S_{\mathrm{N}}\left(t_{i}\right)^{3}= & \frac{3}{v_{\mathrm{p}(2)}} \int_{S_{\mathrm{N}\left(t_{i-1}\right)}}^{S_{0}\left(t_{i}\right)}\left(v_{\mathrm{p}}\left(S, t_{i}\right)-v_{\mathrm{p}(1)}\right\} S^{2} \mathrm{~d} S \\
& +S_{\mathrm{N}}\left(t_{i-1}\right)^{3} .
\end{aligned}
$$

Solving the integral equation eq 27 under the conditions of eq 24, $S_{\mathrm{N}}\left(t_{i}\right)$ and $S_{0}\left(t_{i}\right)$ are obtained.

Differentiation of eq 27 with respect to $t$ gives

$$
\frac{\partial S_{\mathrm{N}}(t)}{\partial t}=\frac{1}{v_{\mathrm{p}(2)} S_{\mathrm{N}}(t)^{2}} \int_{S_{\mathrm{CN}}}^{S_{\mathrm{o}}(t)}\left(\frac{\partial v_{\mathrm{p}}(S, t)}{\partial t}\right) S^{2} \mathrm{~d} S .
$$

Equation 28 is an expression giving the growth rate of the nucleus. Kamide and $\mathrm{Manabe}^{7}$ proposed a somewhat different approach to the estimation of the growth rate using a rather rough approximation. $\partial v(S, t) / \partial t$ in eq 28 can be determined by differentiation of eq 21 with respect to $t$, in the form:

$$
\begin{aligned}
& \frac{\partial v_{\mathrm{p}}(S, t)}{\partial t}=\left(v_{\mathrm{p}}^{0}-v_{\mathrm{p}(1)}\right) \\
& \times\left[\frac { 1 } { 2 \sqrt { \pi } t } \left\{S_{0+} \exp \left(-S_{0+}^{2}\right)\right.\right. \\
& \left.-S_{0-} \exp \left(-S_{0-}^{2}\right)\right\} \\
& -\frac{1}{2 S} \sqrt{\frac{D}{\pi t}}\left\{\exp \left(-S_{0+}^{2}\right)-\exp \left(-S_{0-}^{2}\right)\right\} \\
& -\frac{1}{S} \sqrt{\frac{D}{\pi t}}\left(S_{0+}^{2} \exp \left(-S_{0+}^{2}\right)\right. \\
& \left.-S_{0-}^{2} \exp \left(-S_{0-}^{2}\right)\right] .
\end{aligned}
$$

\section{RESULTS AND DISCUSSION}

\section{Generation of Critical Nuclei (Step b)}

Figures $7 \mathrm{a}$ and $7 \mathrm{~b}$ show the cloud point curve (full line) [in a), $\chi_{0}^{\mathrm{cp}} v s . v_{X}$ and in b), cloud point temperature $\left.T_{\mathrm{CP}} v s . v_{X}\right]$, spinodal curve (broken line) [in a), $\chi_{0}^{\mathrm{SP}}$ vs. $v_{X}$ and in b), $T_{\mathrm{SP}}$ vs. $v_{X}$ ] and critical solution point (unfilled circle) in a case of $X=1 \times 10^{2}$. Figures $7 \mathrm{c}$ and $7 \mathrm{~d}$ show $\Delta G_{v}$ vs. $v_{X}$ curve and $-\left[\left(\Delta \bar{G}-\Delta G_{v}\right) /\right.$ $\tilde{R} T]$ vs. $v_{X}$ curve, respectively. Here, the calculations were carried out under the following conditions; $p_{1}=0.642, p_{2}=0.190$, $\theta=307.1 \mathrm{~K}, \quad \psi_{0}=0.27$ and $V_{0}=108.74 \mathrm{~cm}^{3}$ $\mathrm{mol}^{-1}$. These values except $X$ and $V_{0}$ were determined for atactic polystyrene (PS)/cyclohexane $(\mathrm{CH})$ system by analyzing the critical point data through use of Kamide-Matsuda method in $1984 .^{11} \theta$ and $\psi_{0}$ are substituted into eq 30

$$
T=\frac{\psi_{0} \theta}{\chi_{0}+\psi_{0}-0.5}
$$




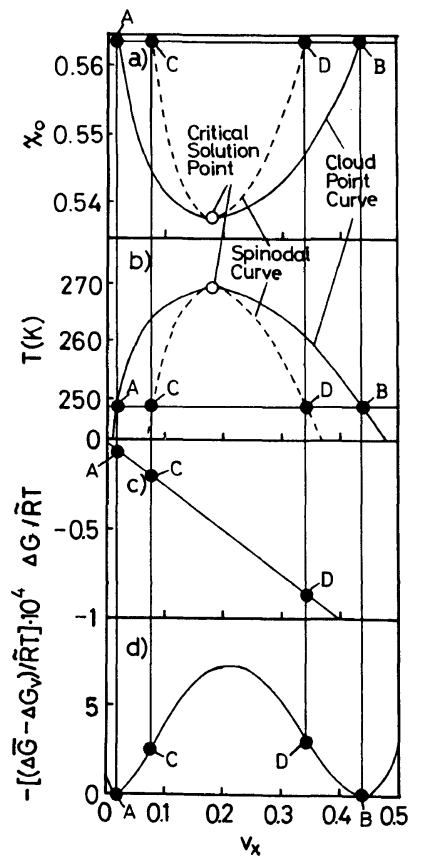

Figure 7. Cloud point curve (solid line), spinodal curve (broken line) and critical solution point (open circle) of monodisperse polymer/single solvent system [a) $\chi_{0} v s$. $v_{X}$ plot, b) $T$ vs. $v_{X}$ plot $]$ together with $\Delta G_{v} / \tilde{R} T$ vs. $v_{X}^{0}$ plot, c) and $-\left[\left(\Delta \bar{G}-\Delta G_{v}\right) / \tilde{R} T\right]$ vs. $v_{X}$ plot, d): Original polymer; monodisperse $\left(X=1 \times 10^{2}\right)$ and $p_{1}=0.642$, $p_{2}=0.190, \theta=307.1 \mathrm{~K}$ and $\psi_{0}=0.27 . v_{X}^{\mathrm{c}}=0.1807$ and $\chi_{0}^{\mathrm{c}}=0.5377 \quad(T=269.5 \mathrm{~K})$ and $\chi_{0}$ (and $\left.T\right)$ at phase separation point $\chi_{0}^{\mathrm{P}}=0.5633$ (and $T=248.8 \mathrm{~K}$ ).

to convert $\chi_{0}$ to $T$. The area, surrounded by cloud point curve and spinodal curve is the metastable region where the critical nuclei are formed as previously mentioned. For $X=1 \times$ $10^{2}$, the critical solution point is $v_{X}^{\mathrm{c}}=0.1807$ and $\chi_{0}^{\mathrm{c}}=0.5377\left(T_{\mathrm{C}}=269.47 \mathrm{~K}\right)$ (see, eq 13 and 14). $\Delta G_{v}$ and $\Delta \bar{G}$ were calculated for the phase separation temperature $T_{\mathrm{P}}=248.8 \mathrm{~K}$ (i.e., $\left.\chi_{0}^{\mathrm{P}}=0.5633\right)$ when $X=1 \times 10^{2}$. In this case, the coexisting compositions are $v_{X(1)}=0.02$ (point A) and $v_{X(2)}=0.4368$ (B) and the spinodal compositions are $v_{X(1)}^{\mathrm{SP}}=0.0774(\mathrm{C})$ and $v_{X(2)}^{\mathrm{SP}}=$ 0.3405 (D). $\Delta G_{v}$ vs. $v_{X}^{0}$ curve is roughly linear in the range $0<v_{X}^{0}<0.5$, but $-\left(\Delta \bar{G}-\Delta G_{v}\right) v s$. $v_{X}^{0}$ curve has two minimums at points $\mathrm{A}$ and $\mathrm{B}$ and two inflection points at points $C$ and $D$ (spinodal points).

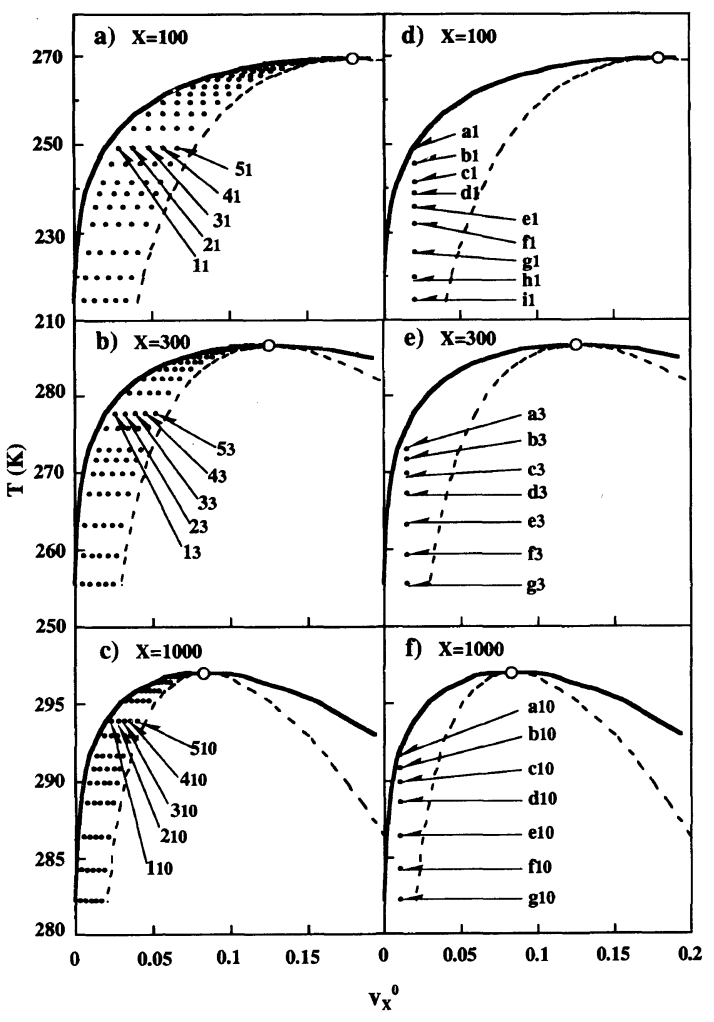

Figure 8. The cloud point curve (broad solid line), spinodal curve (broken line) and critical solution point (unfilled circle) of monodisperse polymer/single solvent system: $p_{1}=0.642, p_{2}=0.190, \theta=307.1 \mathrm{~K}$ and $\psi_{0}=0.27$; - phase separation point (hypothetical one phase); Arrows indicate phase separation points listed in Tables I and II; a) and d), $X=100$; b) and e), $X=300$; c) and f), $X=1000$.

Wolf and Heinrich ${ }^{16}$ measured the interfacial tension (=interfacial free energy) $\sigma$ between the coexisting phases of the systems cyclohexane/polystyrene and methylcyclohexane/polystyrene and revealed that the knowledge of the chain length of the polymer and of the polymer content in the two coexisting phases suffices to predict the $\sigma$ between them, at least for typical vinyl polymers. They presented experimentally the generalized equation

$$
\sigma\left(\mathrm{mN} \mathrm{m}^{-1}\right)=0.153 X^{0.5}\left(v_{X(2)}-v_{X(1)}\right)^{3.85}
$$


where $X$ is the number of monomeric units of the polymer. In the calculation of the size of critical nuclei this equation was employed.

Figure 8a shows the phase separation points (i.e., hypothetical metastable single phase, filled circle) as well as the cloud point curve (solid line), spinodal curve (broken line) and critical solution point (unfilled circle) for PS with $X=1 \times 10^{2} / \mathrm{CH}$. Figures $8 \mathrm{~b}$ and $8 \mathrm{c}$ show results obtained in cases of PS with $X=3 \times 10^{2}$ and $1 \times 10^{3}$, respectively. Larger figures of numbers in Figures $8 \mathrm{a}-8 \mathrm{c}$ like 1 of $1_{1}$ or 5 of $5_{3}$, etc.

Table I. Size of critical nuclei $S_{\mathrm{CN}}$ and activation energy of formation of critical nuclei, $\Delta \phi_{\mathrm{CN}}$, of polystyrene $\left(X\right.$-mer) solution in cyclohexane: Effect of initial polymer concentration $v_{X}^{0}$.

\begin{tabular}{|c|c|c|c|c|c|c|c|c|c|c|}
\hline$X$ & $T_{\mathbf{P}} / \mathbf{K}$ & No. ${ }^{a}$ & $v_{X}^{0}$ & $v_{X(1)}$ & $v_{X(2)}$ & $R$ & $\Delta f_{v} / \mathrm{J} \mathrm{m}^{-3}$ & $\sigma / \mathrm{J} \mathrm{m}^{-2}$ & $S_{\mathrm{CN}} / \mathrm{nm}$ & $\Delta \phi_{\mathrm{CN}} / \mathrm{J}$ \\
\hline \multirow{5}{*}{100} & \multirow{5}{*}{248.8} & $1_{1}$ & 0.0296 & \multirow{5}{*}{0.0200} & \multirow{5}{*}{0.4368} & 42.6 & $-2.67 \times 10^{2}$ & \multirow{5}{*}{$5.26 \times 10^{-5}$} & 394.5 & $3.43 \times 10^{-17}$ \\
\hline & & 21 & 0.0391 & & & 20.8 & $-9.09 \times 10^{2}$ & & 115.8 & $2.96 \times 10^{-18}$ \\
\hline & & 3 & 0.0487 & & & 13.5 & $-1.78 \times 10^{3}$ & & 59.3 & $7.75 \times 10^{-19}$ \\
\hline & & $4_{1}$ & 0.0582 & & & 9.9 & $-2.78 \times 10^{3}$ & & 37.9 & $3.17 \times 10^{-19}$ \\
\hline & & $5_{1}$ & 0.0678 & & & 7.7 & $-3.85 \times 10^{3}$ & & 27.3 & $1.64 \times 10^{-19}$ \\
\hline \multirow{5}{*}{200} & \multirow{5}{*}{268.9} & $1_{2}$ & 0.0276 & \multirow{5}{*}{0.0200} & \multirow{5}{*}{0.3431} & 41.6 & $-8.63 \times 10$ & \multirow{5}{*}{$2.79 \times 10^{-5}$} & 646.8 & $4.89 \times 10^{-17}$ \\
\hline & & 22 & 0.0352 & & & 20.3 & $-2.98 \times 10^{2}$ & & 187.2 & $4.10 \times 10^{-18}$ \\
\hline & & 32 & 0.0427 & & & 13.2 & $-5.89 \times 10^{2}$ & & 94.9 & $1.05 \times 10^{-18}$ \\
\hline & & $4_{2}$ & 0.0503 & & & 9.7 & $-9.26 \times 10^{2}$ & & 60.3 & $4.25 \times 10^{-19}$ \\
\hline & & $5_{2}$ & 0.0579 & & & 7.5 & $-1.29 \times 10^{3}$ & & 43.3 & $2.19 \times 10^{-19}$ \\
\hline \multirow{5}{*}{300} & \multirow{5}{*}{277.6} & $1_{3}$ & 0.0266 & \multirow{5}{*}{0.0200} & \multirow{5}{*}{0.2948} & 40.9 & $-4.28 \times 10$ & \multirow{5}{*}{$1.83 \times 10^{-5}$} & 857.7 & $5.65 \times 10^{-17}$ \\
\hline & & 23 & 0.0331 & & & 19.9 & $-1.49 \times 10^{2}$ & & 246.1 & $4.65 \times 10^{-18}$ \\
\hline & & 3 & 0.0397 & & & 13.0 & $-2.96 \times 10^{2}$ & & 124.1 & $1.18 \times 10^{-18}$ \\
\hline & & $4_{3}$ & 0.0463 & & & 9.5 & $-4.67 \times 10^{2}$ & & 78.5 & $4.74 \times 10^{-19}$ \\
\hline & & $5_{3}$ & 0.0528 & & & 7.4 & $-6.53 \times 10^{2}$ & & 56.2 & $2.43 \times 10^{-19}$ \\
\hline \multirow{5}{*}{500} & \multirow{5}{*}{286.0} & $1_{5}$ & 0.0254 & \multirow{5}{*}{0.0200} & \multirow{5}{*}{0.2409} & 39.8 & $-1.68 \times 10$ & \multirow{5}{*}{$1.02 \times 10^{-5}$} & 1213.6 & $6.30 \times 10^{-17}$ \\
\hline & & 25 & 0.0308 & & & 19.4 & $-5.92 \times 10$ & & 344.8 & $5.09 \times 10^{-18}$ \\
\hline & & 35 & 0.0363 & & & 12.6 & $-1.18 \times 10^{2}$ & & 172.7 & $1.28 \times 10^{-18}$ \\
\hline & & $4_{5}$ & 0.0417 & & & 9.2 & $-1.88 \times 10^{2}$ & & 108.8 & $5.06 \times 10^{-19}$ \\
\hline & & $5_{5}$ & 0.0471 & & & 7.2 & $-2.63 \times 10^{2}$ & & 77.6 & $2.57 \times 10^{-19}$ \\
\hline \multirow{5}{*}{1000} & \multirow{5}{*}{293.8} & $1_{10}$ & 0.0241 & \multirow{5}{*}{0.0200} & \multirow{5}{*}{0.1795} & 38.1 & -4.32 & \multirow{5}{*}{$4.13 \times 10^{-6}$} & 1910.2 & $6.31 \times 10^{-17}$ \\
\hline & & 210 & 0.0282 & & & 18.5 & $-1.54 \times 10$ & & 536.2 & $4.97 \times 10^{-18}$ \\
\hline & & $3_{10}$ & 0.0322 & & & 12.0 & $-3.10 \times 10$ & & 266.2 & $1.22 \times 10^{-18}$ \\
\hline & & $4_{10}$ & 0.0363 & & & 8.8 & $-4.95 \times 10$ & & 166.6 & $4.80 \times 10^{-19}$ \\
\hline & & $5_{10}$ & 0.0404 & & & 6.8 & $-6.98 \times 10$ & & 118.3 & $2.42 \times 10^{-19}$ \\
\hline \multirow{5}{*}{3000} & & $1_{30}$ & 0.0224 & & & 35.1 & $-3.65 \times 10^{-1}$ & & 3755.2 & $4.05 \times 10^{-17}$ \\
\hline & & 230 & 0.0248 & & & 17.1 & -1.32 & & 1037.8 & $3.09 \times 10^{-18}$ \\
\hline & 300.8 & $3_{30}$ & 0.0272 & 0.0200 & 0.1068 & 11.0 & -2.69 & $6.86 \times 10^{-7}$ & 508.9 & $7.44 \times 10^{-19}$ \\
\hline & & $4_{30}$ & 0.0296 & & & 8.0 & -4.35 & & 315.5 & $2.86 \times 10^{-19}$ \\
\hline & & $5_{30}$ & 0.0320 & & & 6.2 & -6.16 & & 222.5 & $1.42 \times 10^{-19}$ \\
\hline & & $1_{50}$ & 0.0218 & & & 33.7 & $-9.24 \times 10^{-2}$ & & 5118.0 & $2.59 \times 10^{-17}$ \\
\hline & & 250 & 0.0236 & & & 16.3 & $-3.39 \times 10^{-1}$ & & 1396.8 & $1.93 \times 10^{-18}$ \\
\hline 5000 & 302.6 & $3_{50}$ & 0.0253 & 0.0200 & 0.0816 & 10.6 & $-6.95 \times 10^{-1}$ & $2.36 \times 10^{-7}$ & 680.1 & $4.58 \times 10^{-19}$ \\
\hline & & $4_{50}$ & 0.0271 & & & 7.7 & -1.13 & & 419.6 & $1.74 \times 10^{-19}$ \\
\hline & & $5_{50}$ & 0.0289 & & & 15.9 & -1.60 & & 294.8 & $8.61 \times 10^{-20}$ \\
\hline
\end{tabular}

a Locations in phase diagram for $X=100,300$, and 1000 are shown in Figures $8 \mathrm{a}-8 \mathrm{c}$. 


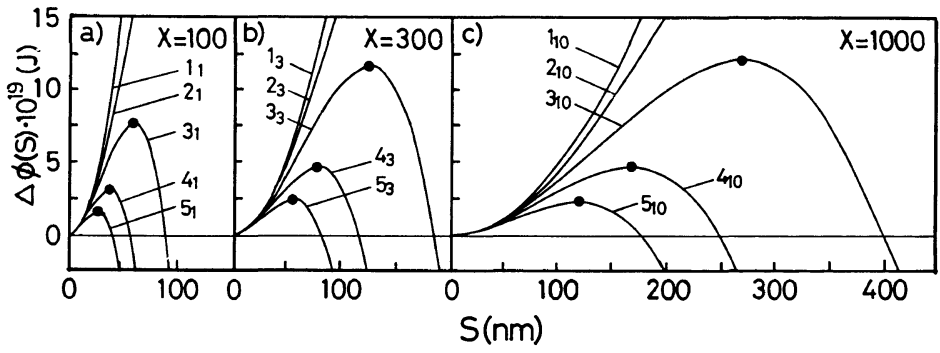

Figure 9. Effect of the free energy change of coagulation per unit volume, $\Delta f_{v}$ on the relation between activation energy of formation of nucleus $\Delta \phi(S)$ and nucleus size $S$ at constant interfacial free energy $\sigma$ between polymer-lean and -rich phases under the following conditions: a), $X=100 ; v_{X(1)}=0.02$; $v_{X(2)}=0.4368 ; \quad \sigma=5.26 \times 10^{-5} \mathrm{~J} \mathrm{~m}^{-2} ; \quad 1_{1}, \quad v_{X}^{0}=0.0296 ; \quad \Delta f_{v}=-2.67 \times 10^{2} \mathrm{~J} \mathrm{~m}^{-3} ; \quad 2_{1}, \quad v_{X}^{0}=0.0391 ;$ $\Delta f_{v}=-9.09 \times 10^{2} \mathrm{~J} \mathrm{~m}^{-3} ; 3_{1}, v_{X}^{0}=0.0487 ; \Delta f_{v}=-1.78 \times 10^{3} \mathrm{~J} \mathrm{~m}^{-3} ; 4_{1}, v_{X}^{0}=0.0582 ; \Delta f_{v}=-2.78 \times 10^{3}$ $\left.\mathrm{J} \mathrm{m}^{-3} ; 5, v_{X}^{0}=0.0678 ; \Delta f_{v}=-3.85 \times 10^{3} \mathrm{~J} \mathrm{~m}^{-3} ; \mathrm{b}\right), X=300 ; v_{X(1)}=0.02 ; v_{X(2)}=0.2948 ; \sigma=1.83 \times 10^{-5}$ $\mathrm{J} \mathrm{m}^{-2} ; 1_{3}, v_{X}^{0}=0.0266 ; \Delta f_{v}=-4.28 \times 10 \mathrm{~J} \mathrm{~m}^{-3} ; 2_{3}, v_{X}^{0}=0.0331 ; \Delta f_{v}=-1.49 \times 10^{2} \mathrm{~J} \mathrm{~m}^{-3} ; 3_{3}, v_{X}^{0}=0.0397$; $\Delta f_{v}=-2.96 \times 10^{2} \mathrm{~J} \mathrm{~m}^{-3} ; 4_{3}, v_{X}^{0}=0.0463 ; \Delta f_{v}=-4.67 \times 10^{2} \mathrm{~J} \mathrm{~m}^{-3} ; 5 s_{3}, v_{X}^{0}=0.0528 ; \Delta f_{v}=-6.53 \times 10^{2}$ $\left.\mathrm{J} \mathrm{m}^{-3} ; \mathrm{c}\right), X=1000 ; v_{X(1)}=0.02 ; v_{X(2)}=0.1795 ; \sigma=4.13 \times 10^{-6} \mathrm{~J} \mathrm{~m}^{-2} ; 1_{10}, v_{X}^{0}=0.0241 ; \Delta f_{v}=-4.32 \mathrm{~J} \mathrm{~m}^{-3}$; $2_{10}, v_{X}^{0}=0.0282 ; \Delta f_{v}=-1.54 \times 10 \mathrm{~J} \mathrm{~m}^{-3} ; 3_{10}, v_{X}^{0}=0.0322 ; \Delta f_{v}=-3.10 \times 10 \mathrm{~J} \mathrm{~m}^{-3} ; 4_{10}, v_{X}^{0}=0.0363$; $\Delta f_{v}=-4.95 \times 10 \mathrm{~J} \mathrm{~m}^{-3} ; 5_{10}, v_{X}^{0}=0.0404 ; \Delta f_{v}=-6.98 \times 10 \mathrm{~J} \mathrm{~m}^{-3}$; closed circle, $\Delta \phi(S)$ and $S$ of critical nucleus (i.e., $\Delta \phi_{\mathrm{CN}}$ and $S_{\mathrm{CN}}$ ).

correspond to positions where a line between a cloud point and a spinodal point at the constant $T_{\mathbf{P}}$ are divided into six equal parts. Small suffixes (1, 3, and 10) mean $X / 100$. Accordingly, $1_{1}$ is the nearest point to a cloud point and $5_{1}$ is the nearest to a spinodal point.

Table I collects the values of $\Delta f_{v}, \sigma$ and $S_{\mathrm{CN}}$ which were calculated for PS with $X=1 \times 10^{2}$ $5 \times 10^{3}$ in $\mathrm{CH}$ at $v_{\mathbf{p}(1)}=0.0200$. Here, interfacial free energy $\sigma$ between polymer-lean and -rich phases of PS/CH solution was determined by use of eq 31. The radius of critical nuclei $S_{\mathrm{CN}}$ ranges from the order of several thousand $\mathrm{nm}$ to several ten $\mathrm{nm}$, decreasing with increase in initial concentration or when the phase separation point comes nearer the spinodal curve. $S_{\mathrm{CN}}$ becomes smaller for smaller $X$. For $X=1 \times 10^{2}$ or $2 \times 10^{2}, S_{\mathrm{CN}}$ had magnitude of the same order as those of the primary particles observed by EM.

Figure 9 shows relation between radius of nuclei $S$ and $\Delta \phi(S)$ at a given phase separation point. Numbers on curves are those $\left(1_{1}-5_{1}\right.$, $1_{3}-5_{3}$, and $1_{10}-5_{10}$ ) listed in Table I and are also shown in Figures $8 \mathrm{a}-8 \mathrm{c}$. $S_{\mathrm{CN}}$ of critical nuclei generated near the cloud point curve were larger than those near a spinodal curve, but $\Delta \phi_{\mathrm{CN}}$ became smaller when the phase separation occurred near the spinodal curve, indicating that nucleation tends to occur much more easily near the spinodal curve.

Figures $10 \mathrm{a}-10 \mathrm{~d}$ show effects of $v_{X}^{0}$ on $R$, $\Delta f_{v}, S_{\mathrm{CN}}$, and $\Delta \phi_{\mathrm{CN}}$ under the phase separation condition, shown as closed circles in Figure 8a. If solutions having different initial polymer concentrations obey to phase separation at the constant temperature, $R, \Delta f_{v}, S_{\mathrm{CN}}$, and $\Delta \phi_{\mathrm{CN}}$ become smaller at larger $v_{X}^{0}$. Figures $11 \mathrm{a}-11 \mathrm{c}$ show $S_{\mathrm{CN}}$ generated at phase separation points as shown in Figures 8a-8c. In the figures, data points for $S_{\mathrm{CN}}>500 \mathrm{~nm}$ were omitted.

When a solution is cooled from a single phase state to bring about two-phase separation, the solution passes through the cloud point and $\Delta f_{v}$ attains the minimum on the cloud point curve and accordingly, $S_{\mathrm{CN}}$ on the cloud point is the maximum. Table II shows results calculated on phase separation points as shown in Figures $8 \mathrm{~d}-8 \mathrm{f}$ for PS solutions with $X=1 \times 10^{2}, 3 \times 10^{2}$, and $1 \times 10^{3}$. In these figures, point a is the nearest to the cloud point curve and suffixes (small figures) mean $X / 100$. Critical nuclei seldom generate on the cloud point curve and the activation energy of 


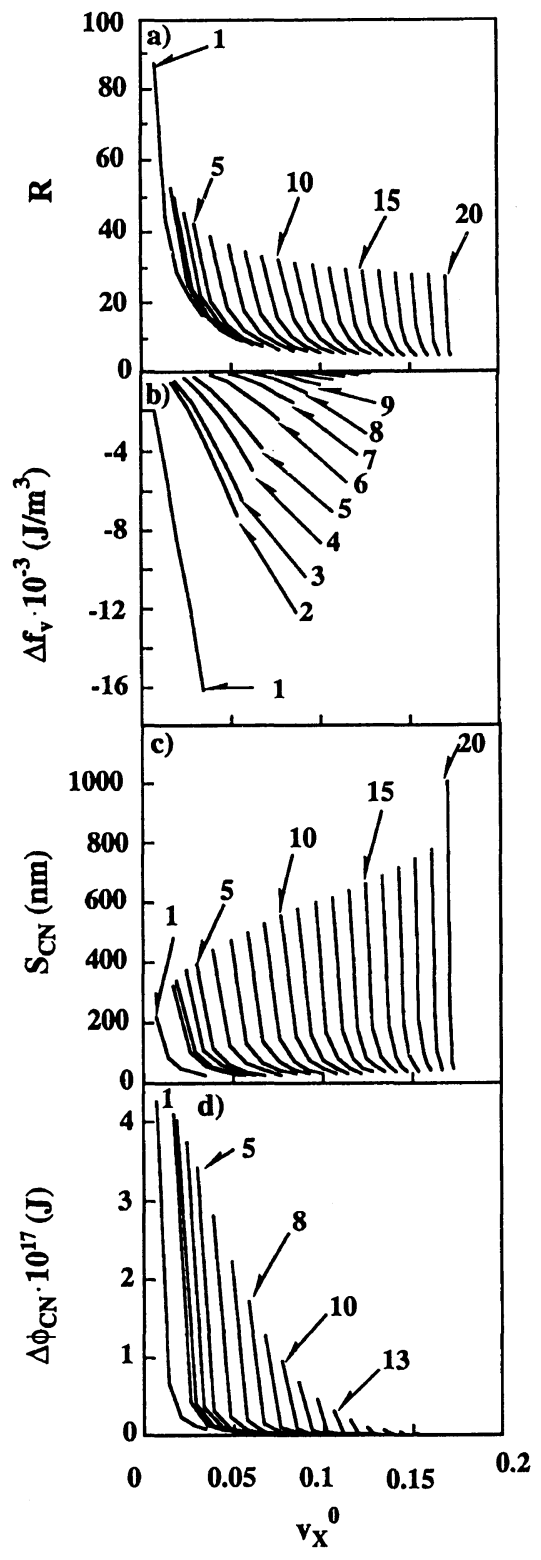

Figure 10. Effects of initial polymer concentration $v_{X}^{0}$ on phase volume ratio $R(a)$, free energy change of coagulation per unit volume $\Delta f_{v}(\mathrm{~b})$, radius of critical nucleus $S_{\mathrm{CN}}$ (c) and activation energy of formation of critical nucleus $\Delta \phi_{\mathrm{CN}}(\mathrm{d}): X=100$; numbers mean phase separation temperature $T_{\mathrm{P}} ; 1, T_{\mathrm{P}}=214.4 \mathrm{~K} ; 2, T_{\mathrm{P}}=238.7 \mathrm{~K}$; $3, T_{\mathrm{P}}=241.1 \mathrm{~K} ; 4, T_{\mathrm{P}}=245.5 \mathrm{~K} ; 5, \quad T_{\mathrm{P}}=248.8 \mathrm{~K} ; 6$, $T_{\mathrm{P}}=253.4 \mathrm{~K} ; 7, T_{\mathrm{P}}=256.8 \mathrm{~K} ; 8, T_{\mathrm{P}}=259.3 \mathrm{~K} ; 9, T_{\mathrm{P}}=$ $261.4 \mathrm{~K} ; 10, T_{\mathrm{P}}=263.0 \mathrm{~K} ; 11, T_{\mathrm{P}}=264.4 \mathrm{~K} ; 12, T_{\mathrm{P}}=265.5$ $\mathrm{K} ; 13, T_{\mathrm{P}}=266.4 \mathrm{~K} ; 14, T_{\mathrm{P}}=267.2 \mathrm{~K} ; 15, T_{\mathrm{P}}=267.9 \mathrm{~K} ; 16$, $T_{\mathrm{P}}=268.4 \mathrm{~K} ; 17, \quad T_{\mathrm{P}}=268.8 \mathrm{~K} ; 18, \quad T_{\mathrm{P}}=269.1 \mathrm{~K} ; 19$, $T_{\mathrm{P}}=269.3 \mathrm{~K} ; 20, T_{\mathrm{P}}=269.4 \mathrm{~K}$.
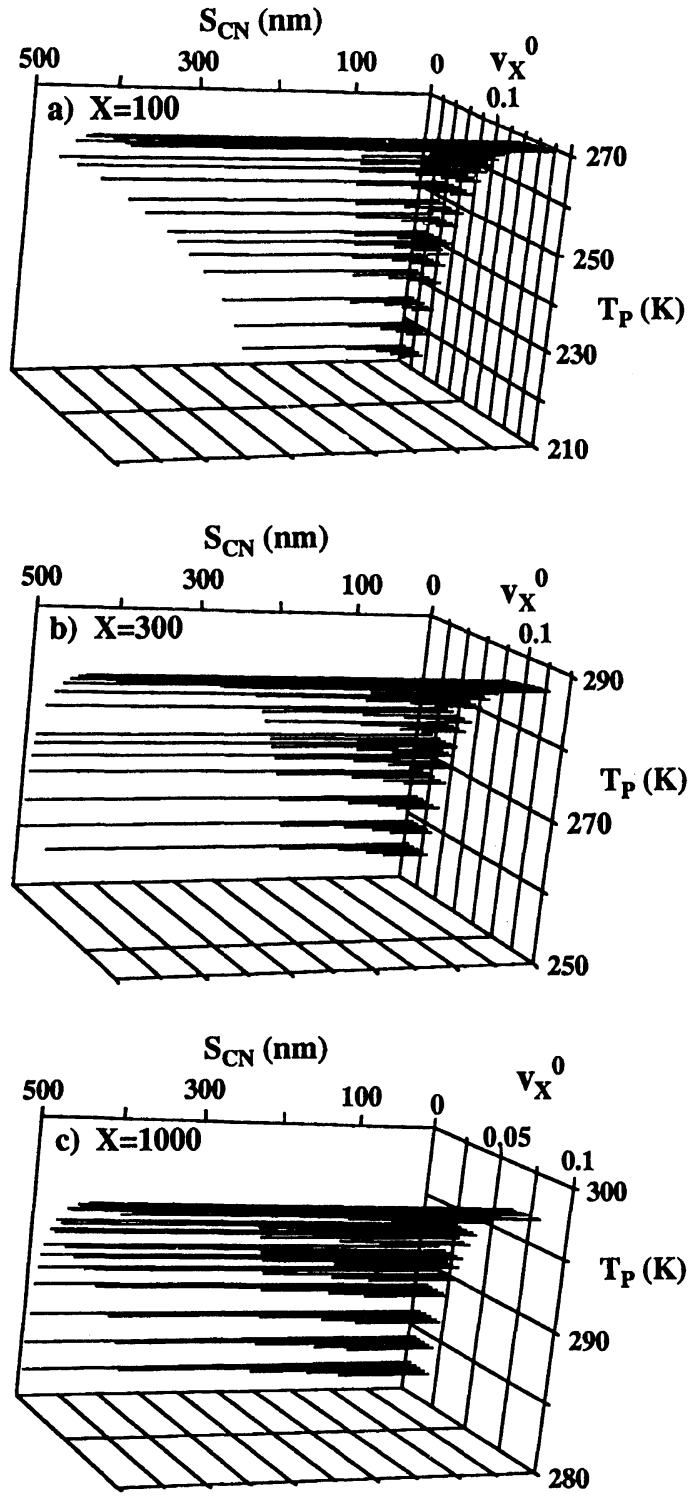

Figure 11. Three dimensional views of relation between radius of critical nucleus $S_{\mathrm{CN}}$, phase separation points $\left(v_{X}^{0}\right.$ and $T_{\mathrm{p}}$ ) on a phase diagram: a), $\left.X=100 ; \mathrm{b}\right), X=300$; c), $X=1000$ : Data points of $S_{\mathrm{CN}}>500 \mathrm{~nm}$ are not shown here.

formation of critical nucleus $\Delta \phi_{\mathrm{CN}}$ and $S_{\mathrm{CN}}$ are the smallest on the spinodal curve.

\section{Growth of Nucleus (Step c) to Primary Particle} (Step d)

Figure 12 demonstrates the concentration 
Formation of Porous Polymeric Membrane I.

Table II. Size of critical nuclei $S_{\mathrm{CN}}$ and activation energy of formation of critical nuclei, $\Delta \phi_{\mathrm{CN}}$, of polystyrene ( $X$-mer) solutions in cyclohexane: Effect of $T_{\mathrm{p}}$

\begin{tabular}{|c|c|c|c|c|c|c|c|c|c|c|}
\hline$X$ & $T_{\mathrm{P}} / \mathrm{K}$ & No. ${ }^{a}$ & $v_{X}^{0}$ & $v_{X(1)}$ & $v_{X(2)}$ & $R$ & $\Delta f_{v} / \mathrm{J} \mathrm{m}^{-3}$ & $\sigma / \mathrm{J} \mathrm{m}^{-2}$ & $S_{\mathrm{CN}} / \mathrm{nm}$ & $\Delta \phi_{\mathrm{CN}} / \mathbf{J}$ \\
\hline \multirow{9}{*}{100} & 248.8 & $a_{1}$ & \multirow{9}{*}{0.0210} & 0.0200 & 0.4367 & 433.8 & -3.18 & $5.26 \times 10^{-5}$ & 33064.8 & $2.41 \times 10^{-13}$ \\
\hline & 245.5 & $b_{1}$ & & 0.0150 & 0.4567 & 73.1 & $-1.52 \times 10^{2}$ & $6.58 \times 10^{-5}$ & 866.7 & $2.07 \times 10^{-16}$ \\
\hline & 241.1 & $c_{1}$ & & 0.0100 & 0.4818 & 42.1 & $-6.74 \times 10^{2}$ & $8.49 \times 10^{-5}$ & 252.0 & $2.26 \times 10^{-17}$ \\
\hline & 238.7 & $d_{1}$ & & 0.0080 & 0.4944 & 36.5 & $-1.08 \times 10^{3}$ & $9.54 \times 10^{-5}$ & 176.7 & $1.25 \times 10^{-17}$ \\
\hline & 235.7 & $e_{1}$ & & 0.0060 & 0.5094 & 32.7 & $-1.70 \times 10^{3}$ & $1.09 \times 10^{-4}$ & 128.4 & $7.52 \times 10^{-18}$ \\
\hline & 231.7 & $f_{1}$ & & 0.0040 & 0.5287 & 29.9 & $-2.69 \times 10^{3}$ & $1.28 \times 10^{-4}$ & 94.8 & $4.81 \times 10^{-18}$ \\
\hline & 225.3 & $g_{1}$ & & 0.0020 & 0.5574 & 28.3 & $-4.61 \times 10^{3}$ & $1.59 \times 10^{-4}$ & 69.0 & $3.17 \times 10^{-18}$ \\
\hline & 219.5 & $\mathrm{~h}_{1}$ & & 0.0010 & 0.5819 & 28.1 & $-6.63 \times 10^{3}$ & $1.89 \times 10^{-4}$ & 57.0 & $2.57 \times 10^{-18}$ \\
\hline & 214.1 & $i_{1}$ & & 0.0005 & 0.6031 & 28.5 & $-8.66 \times 10^{3}$ & $2.18 \times 10^{-4}$ & 50.3 & $2.30 \times 10^{-18}$ \\
\hline \multirow{8}{*}{300} & 275.7 & $a_{3}$ & \multirow{8}{*}{0.0154} & 0.0150 & 0.3125 & 808.8 & $-2.27 \times 10^{-1}$ & \multicolumn{2}{|c|}{$2.49 \times 10^{-5} 219513.4$} & $5.03 \times 10^{-12}$ \\
\hline & 273.0 & $b_{3}$ & & 0.0100 & 0.3350 & 59.5 & $-6.56 \times 10$ & $3.50 \times 10^{-5}$ & 1066.4 & $1.67 \times 10^{-16}$ \\
\hline & 271.6 & $c_{3}$ & & 0.0080 & 0.3462 & 44.9 & $-1.44 \times 10^{2}$ & $4.08 \times 10^{-5}$ & 564.9 & $5.45 \times 10^{-17}$ \\
\hline & 269.7 & $\mathrm{~d}_{3}$ & & 0.0060 & 0.3598 & 36.8 & $-2.82 \times 10^{2}$ & $4.85 \times 10^{-5}$ & 344.4 & $2.41 \times 10^{-17}$ \\
\hline & 267.2 & $\mathrm{e}_{3}$ & & 0.0040 & 0.3772 & 31.8 & $-5.28 \times 10^{2}$ & $5.96 \times 10^{-5}$ & 225.8 & $1.27 \times 10^{-17}$ \\
\hline & 263.1 & $\mathrm{f}_{3}$ & & 0.0020 & 0.4032 & 29.0 & $-1.04 \times 10^{3}$ & $7.87 \times 10^{-5}$ & 151.2 & $7.54 \times 10^{-18}$ \\
\hline & 259.2 & $\mathrm{~g}_{3}$ & & 0.0010 & 0.4256 & 28.6 & $-1.62 \times 10^{3}$ & $9.79 \times 10^{-5}$ & 120.9 & $5.99 \times 10^{-18}$ \\
\hline & 255.6 & $\mathrm{~h}_{3}$ & & 0.0005 & 0.4451 & 28.9 & $-2.23 \times 10^{3}$ & $1.17 \times 10^{-4}$ & 105.1 & $5.41 \times 10^{-18}$ \\
\hline \multirow{7}{*}{1000} & 291.6 & $a_{10}$ & \multirow{7}{*}{0.0108} & 0.0100 & 0.2127 & 266.2 & $-4.43 \times 10^{-1}$ & $1.04 \times 10^{-5}$ & 46862.7 & $9.54 \times 10^{-14}$ \\
\hline & 290.8 & $\mathrm{~b}_{10}$ & & 0.0080 & 0.2220 & 76.6 & -6.99 & $1.28 \times 10^{-5}$ & 3661.1 & $7.18 \times 10^{-16}$ \\
\hline & 289.8 & $c_{10}$ & & 0.0060 & 0.2332 & 46.7 & $-2.57 \times 10$ & $1.61 \times 10^{-5}$ & 1252.0 & $1.06 \times 10^{-16}$ \\
\hline & 288.5 & $d_{10}$ & & 0.0040 & 0.2476 & 35.0 & $-6.82 \times 10$ & $2.11 \times 10^{-5}$ & 617.8 & $3.37 \times 10^{-17}$ \\
\hline & 286.3 & $e_{10}$ & & 0.0020 & 0.2692 & 29.5 & $-1.72 \times 10^{2}$ & $3.01 \times 10^{-5}$ & 350.6 & $1.55 \times 10^{-17}$ \\
\hline & 284.2 & $\mathrm{f}_{10}$ & & 0.0010 & 0.2878 & 28.4 & $-2.98 \times 10^{2}$ & $3.95 \times 10^{-5}$ & 264.7 & $1.16 \times 10^{-17}$ \\
\hline & 282.2 & $\mathrm{~g}_{10}$ & & 0.0005 & 0.3040 & 28.6 & $-4.37 \times 10^{2}$ & $4.91 \times 10^{-5}$ & 224.7 & $1.04 \times 10^{-17}$ \\
\hline
\end{tabular}

a Locations in phase diagram are shown in Figures $8 \mathrm{~d}-8 \mathrm{f}$.

profile of a critical nucleus and its surrounding. $\mathrm{PS} / \mathrm{CH}$ system is employed as a model system where $X=500, p_{1}=0.642, p_{2}=0.190$, entropy parameter $\psi_{0}=0.27$, and Flory theta temperature $\theta=305.1 \mathrm{~K}^{1{ }^{1,12}}$ In the figure, $v_{\mathrm{p}}^{0}=0.0147$, $T_{\mathrm{P}}=270.22 \mathrm{~K}$ (i.e., $\left.\chi_{\mathrm{P}}^{0}=0.5350\right), v_{\mathrm{p}(1)}=0.001$, $v_{\mathrm{p}(2)}=0.362, \quad R=25.387, \quad \Delta f_{v}=-930 \mathrm{~J} \mathrm{~m}^{-3}$, $\Delta t=0.005 \mu \mathrm{s}, D=2.5 \times 10^{-10} \mathrm{~m}^{2} \mathrm{~s}^{-1}$, and $\sigma=$ $5 \times 10^{-6} \mathrm{~J} \mathrm{~m}^{-2}$ (so, $S_{\mathrm{CN}}=S_{\mathrm{N}}(0)=10.75 \mathrm{~nm}$ and $\left.S_{0}(0)=32.004 \mathrm{~nm}\right)$ were assumed. From the figure, the growth of the nucleus $S_{N}(t)$ and the expansion of the local equilibrium region $S_{0}(t)$ with time can be readily understood.

Figure 13 shows the effect of $\sigma$ on the plots of $S_{\mathrm{N}}(t)$ or $S_{0}(t)$ against $t$. Under the conditions employed here, critical nuclei grow up after $0.4 \mu$ s of its birth to a particle with radius of ca. $750 \mathrm{~nm}$ and at the same time, the local equilibrium region expands to as wide as $c a$. $2000 \mathrm{~nm}$, irrespective of $\sigma$.

As the nucleus grows in this manner, the surrounding sphere with radius of $S_{0}$ also continues to become bigger. During the growth of the nucleus, the outer homogeneous region generates a new critical nucleus (see, Figure 14). Ultimately (at a given time $t=t_{\mathrm{p}}$ ) the original outer homogeneous phase (hatched area) will disappear completely, due to consumption by continuous expansion of the $S_{0}$ sphere and further generation of critical nuclei. All the nuclei (i.e., the particles) at this instant $\left(t=t_{\mathrm{P}}\right)$ are conventionally defined as primary particles (Figure 14).

We assume that nucleation is always absolutely sporadic and spinodal decomposition is never predominant, then the rate of 


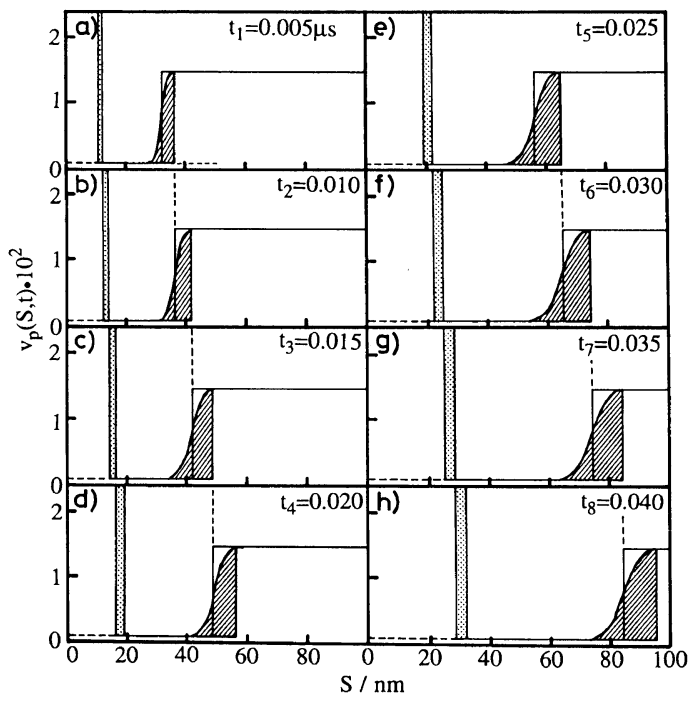

Figure 12. Concentration profile of nucleus and its surroundings together with diffusion $v_{\mathrm{p}}(S, t)$ (hatched area) and increase of radius of nucleus (shadowed area) of polystyrene/cyclohexane system $\left(X=500, p_{1}=0.642, p_{2}=\right.$ $0.190, \psi_{0}=0.27$, and $\left.\theta=305.1 \mathrm{~K}\right)$ : Initial polymer volume fraction, $v_{\mathrm{p}}^{0}=0.0147$; concentration of coexisting phases, $v_{\mathrm{p}(1)}=0.001$ and $v_{\mathrm{p}(2)}=0.362$ (accordingly, $R=25.387$ ); difference of free energy between before and after phase separation, $\Delta f_{v}=-930 \mathrm{~J} \mathrm{~m}^{-3}$; phase separation temperature, $T_{\mathrm{P}}=270.22 \mathrm{~K}$ : Interfacial free energy, $\sigma=5 \times 10^{-6}$ $\mathrm{J} \mathrm{m}^{-2}$ [accordingly, $S_{\mathrm{CN}}=S_{\mathrm{N}}(0)=10.75 \mathrm{~nm}$ and $S_{0}(0)=$ $32.00 \mathrm{~nm}$ ] and diffusion coefficient, $D=2.5 \times 10^{-10} \mathrm{~m}^{2} \mathrm{~s}^{-2}$ assumed; a), $t=0.005 \mu \mathrm{s}$; b), $t=0.010 \mu \mathrm{s} ; \mathrm{c}), t=0.015 \mu \mathrm{s}$; d), $t=0.020 \mu \mathrm{s} ; \quad$ e),$\quad t=0.025 \mu \mathrm{s} ; \quad$ f), $t=0.030 \mu \mathrm{s} ; \quad \mathrm{g})$, $t=0.035 \mu \mathrm{s} ; \mathrm{h}), t=0.040 \mu \mathrm{s}$.

production of critical nuclei per unit volume is given by

$$
\frac{\mathrm{d} N_{\mathrm{CN}}}{\mathrm{d} t}=k_{\mathrm{CN}} \exp \left(-\frac{\Delta \phi_{\mathrm{CN}}}{k_{\mathrm{B}} T}\right)
$$

with

$$
k_{\mathrm{CN}}=k_{\mathrm{CN}}^{\prime}\left\{1-\frac{N_{\mathrm{CN}}(t)}{N_{\mathrm{CN}}(\infty)}\right\} .
$$

$N_{\mathrm{CN}}$ is the number of critical nuclei per unit volume (number $\mathrm{m}^{-3}$ ), $N_{\mathrm{CN}}(t), N_{\mathrm{CN}}$ at $t$, $N_{\mathrm{CN}}(\infty), N_{\mathrm{CN}}$ at $t=\infty$ and $k_{\mathrm{CN}}^{\prime}$, the rate constant (number $\mathrm{m}^{-3} \cdot \mathrm{s}^{-1}$ ) and $\Delta \phi_{\mathrm{CN}}$ can be calculated using eq 16 . Here, nucleation is considered to be described by the same formula as that for the zeroth order reaction. However,

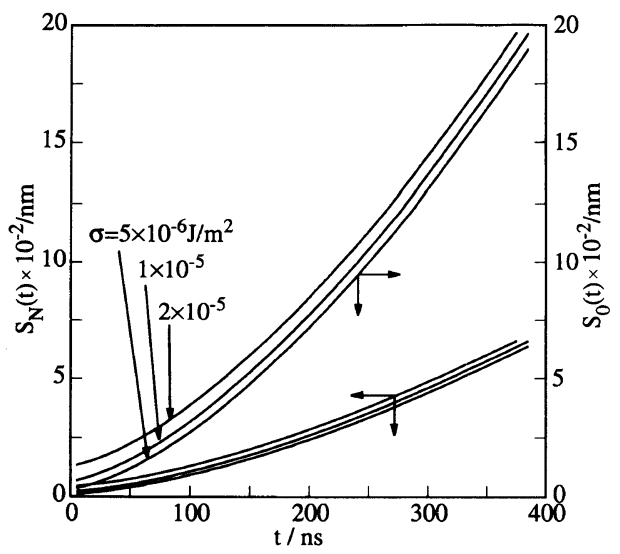

Figure 13. Time dependence of radius of nucleus $S_{\mathrm{N}}(t)$ and that of its surrounding sphere $S_{0}(t)$ of polystyrene/cyclohexane system $\left(X=500, p_{1}=0.642, p_{2}=\right.$ $0.190, \psi_{0}=0.27$, and $\left.\theta=305.1 \mathrm{~K}\right)$ : Initial polymer volume fraction, $v_{\mathrm{p}}^{0}=0.0147$; concentration of two coexisting phases, $v_{\mathrm{p}(1)}=0.001$ and $v_{\mathrm{p}(2)}=0.362$ (accordingly, $R=$ 25.387); difference of free energy between before and after phase separation, $\Delta f_{v}=-930 \mathrm{~J} \mathrm{~m}^{-3}$; phase separation temperature $T_{\mathrm{P}}=270.22 \mathrm{~K}$; interfacial free energy, $\sigma=5 \times$ $10^{-6} \mathrm{~J} \mathrm{~m}^{-2}$ [accordingly, $S_{\mathrm{CN}}=S_{\mathrm{N}}(0)=10.75 \mathrm{~nm}$ and $S_{0}(0)=32.004 \mathrm{~nm}$ ], $\sigma=1 \times 10^{-5} \mathrm{~J} \mathrm{~m}^{-2} \quad$ [accordingly, $S_{\mathrm{CN}}=21.505 \mathrm{~nm}$ and $\left.S_{0}(0)=64.024 \mathrm{~nm}\right]$ and $\sigma=2 \times 10^{-5}$ $\mathrm{J} \mathrm{m}^{-2}$ [accordingly, $S_{\mathrm{CN}}=43.01 \mathrm{~nm}$ and $S_{0}(0)=128.04$ $\mathrm{nm}]$; diffusion coefficient, $D=2.5 \times 10^{-10} \mathrm{~m}^{2} \mathrm{~s}^{-1}$.

the nucleation does not continue without limits as was confirmed repeatedly by a large number of actual experiments if available surveys are to be believed, and it will stop at the instant when the phase equilibrium of total system is realized (i.e., $t=t_{\mathrm{p}}$; see, Figure 14).

Substitution of eq 33 into eq 32 yields

$$
\frac{\mathrm{d} N_{\mathrm{CN}}(t)}{\mathrm{d} t}=v\left\{1-\frac{N_{\mathrm{CN}}(t)}{N_{\mathrm{CN}}(\infty)}\right\}
$$

with

$$
v \equiv k_{\mathrm{CN}}^{\prime} \exp \left(-\frac{\Delta \phi_{\mathrm{CN}}}{k_{\mathrm{B}} T}\right)
$$

By solving the differential equation (eq 34), we obtain

$$
N_{\mathrm{CN}}(t)=N_{\mathrm{CN}}(\infty)\left[1-\exp \left(-\frac{v}{N_{\mathrm{CN}}(\infty)} t\right)\right] .
$$



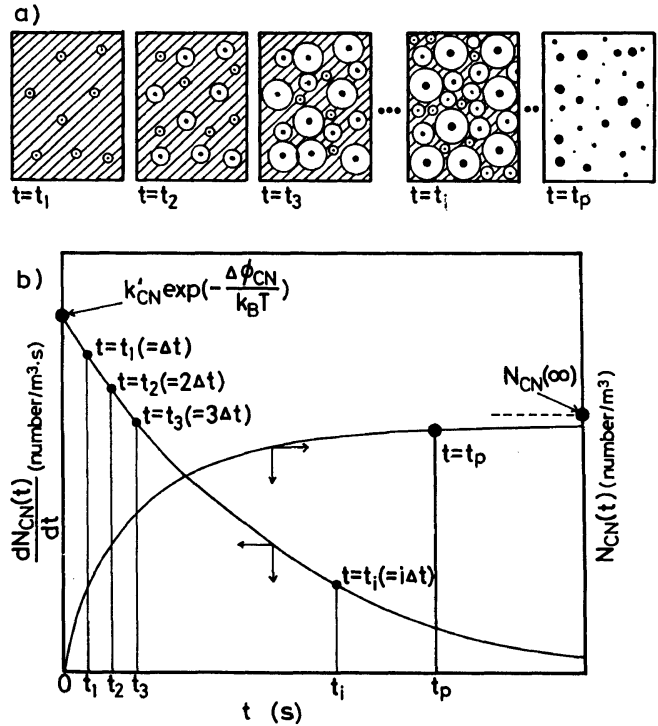

Figure 14. Schematic representation of nucleation and growth of nuclei [a)] and time dependence of nucleation $N_{\mathrm{CN}}(t)$ and rate of nucleation $\mathrm{d} N_{\mathrm{CN}} / \mathrm{d} t$ of critical nuclei [b)]: a), , nucleus (polymer-rich phase); $\bigcirc$, surrounding sphere (polymer-lean phase); hatched area, outer homogeneous phase.

Combination of eq 34 and 35 gives

$$
\frac{\mathrm{d} N_{\mathrm{CN}}(t)}{\mathrm{d} t}=v \exp \left(-\frac{v}{N_{\mathrm{CN}}(\infty)} t\right) .
$$

The total volume of $S_{0}$ spheres including growing particles at $t, V_{0}(t)$ is expressed as

$$
V_{0}(t)=\int_{0}^{t} \frac{\mathrm{d} N_{\mathrm{CN}}(t)}{\mathrm{d} t} \frac{4 \pi}{3} S_{0}(t-\tau)^{3} \mathrm{~d} \tau
$$

where $\tau$ is the time of formation of nucleus and $t-\tau$ is the growing time of nucleus at $t . S_{0}$ and $S_{\mathrm{N}}$ are the functions of $t-\tau$ [i.e., $S_{0}=S_{0}(t-\tau)$ and $\left.S_{\mathrm{N}}=S_{\mathrm{N}}(t-\tau)\right]$.

At $t=t_{\mathrm{P}}, V(t)=1$ holds. In other words, in order to estimate $t_{\mathrm{P}}$, the following equation should be solved.

$$
\int_{0}^{t_{\mathrm{P}}} \frac{\mathrm{d} N_{\mathrm{CN}}(t)}{\mathrm{d} t} \frac{4 \pi}{3} S_{0}\left(t_{\mathrm{P}}-\tau\right)^{3} \mathrm{~d} \tau=1 .
$$

Since $\mathrm{d} N_{\mathrm{CN}} / \mathrm{d} t$ can be evaluated from $N_{\mathrm{CN}}(\infty)$ and $v$ [accordingly, $k_{\mathrm{CN}}^{\prime}, \Delta \phi_{\mathrm{CN}}$ and $T$ \{see, eq $35\}]$ by eq 37 and $S_{0}(t-\tau)$ together with
$S_{N}(t-\tau)$ can be calculated by solving simultaneous equations [eq 24 and 27], $t_{\mathrm{p}}$ can be unambiguously determined by eq 39 under given phase separation conditions. Here, $N_{\mathrm{CN}}(\infty)$ (number $\mathrm{m}^{-3}$ ) should be below the number of polymer molecules (in this case, monodisperse polymer) per unit volume. For example, in the case of the weight fraction of polymer with molecular weight $M=3 \times 10^{4}$ $\mathrm{g} \mathrm{mol}^{-1}, w_{X}=0.03$, the following relation

$$
\begin{aligned}
N_{\mathrm{CN}}(\infty) & \leq \frac{w_{X} \times d_{\mathrm{PL}} \times 10^{6}}{\frac{M}{N_{\mathrm{A}}}}\left(=\frac{0.03 \times 1 \times 10^{6}}{3 \times 10^{4}} N_{\mathrm{A}}\right) \\
& =N_{\mathrm{A}}\left(=6.023 \times 10^{23} \text { number }^{-3}\right),
\end{aligned}
$$

should be satisfied. Here, $d_{\mathrm{PL}}$ is the density of polymer and $N_{\mathrm{A}}$ is Avogadro's constant.

Figure 15 shows the effect of $\sigma$ and $N_{\mathrm{CN}}(\infty)$ on the relations between $t_{\mathrm{p}}$, obtained by solving an integral equation [eq 39], and $k_{\mathrm{CN}}^{\prime}$ (Figures $15 \mathrm{a}$ and $15 \mathrm{~b}$ ) and on the relations between $N_{\mathrm{CN}}\left(t_{\mathrm{P}}\right)$, calculated by substituting $t_{\mathrm{P}}$ into eq 36 , and $k_{\mathrm{CN}}^{\prime}$ (Figures $15 \mathrm{c}$ and $15 \mathrm{~d}$ ), respectively. In Figures $15 \mathrm{a}$ and $15 \mathrm{c}, \Delta \phi_{\mathrm{CN}}=2.42 \times 10^{-21} \mathrm{~J}$, (accordingly, $\left.\exp \left(\Delta \phi_{\mathrm{CN}} / k_{\mathrm{B}} T\right)=0.523\right)$ was estimated by putting and $\sigma=5 \times 10^{-5} \mathrm{~J} \mathrm{~m}^{-2}$ into eq 16 and Figures $15 \mathrm{~b}$ and $15 \mathrm{~d}, \Delta \phi_{\mathrm{CN}}=1.94 \times$ $10^{-20} \mathrm{~J}$ (accordingly, $\exp \left(\Delta \phi_{\mathrm{CN}} / k_{\mathrm{B}} T\right)=5.56 \times$ $10^{-3}$ ) was estimated, in a similar manners from $\sigma=1 \times 10^{-5} \mathrm{~J} \mathrm{~m}^{-2}$ and eq 16 . Other conditions are the same as those in Figure 13. At $\sigma=2 \times 10^{-5}, \Delta \phi_{\mathrm{CN}}=1.55 \times 10^{-19} \mathrm{~J}$ (accordingly, $\left.\exp \left(\Delta \phi_{\mathrm{CN}} / k_{\mathrm{B}} T\right)=9.07 \times 10^{-19}\right)$ is obtained and eq 39 can not be solved numerically due to extremely small magnitude of the probability $\exp \left(\Delta \phi_{\mathrm{CN}} / k_{\mathrm{B}} T\right)=9.07 \times 10^{-19}$. As $k_{\mathrm{CN}}^{\prime}$ increases $t_{\mathrm{P}}$ decreases monotonically, approaching an asymptotic value which is smaller for larger $\sigma$ and for larger $N_{\mathrm{CN}}(\infty)$. $N_{\mathrm{CN}}\left(t_{\mathrm{P}}\right)$ increases with $k_{\mathrm{CN}}^{\prime}$, attaining at $N_{\mathrm{CN}}(\infty)$. Figure 15 implies that in a relatively early stage of phase separation all possible nuclei generate completely and thereafter the separation 


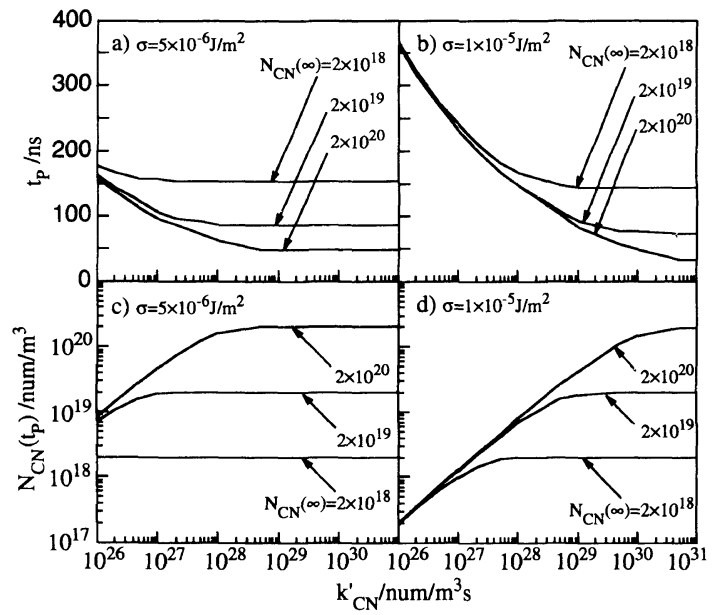

Figure 15. Relations between the time needed for attainment of equilibrium $t_{\mathrm{P}}$ and rate constant of nucleation $k_{\mathrm{CN}}^{\prime}$ (eq 33) [a) and b)] and relations between the nuclei density $N_{\mathrm{CN}}(\infty)$ and $k_{\mathrm{CN}}^{\prime}$ [c) and d)] of polystyrene/cyclohexane system: $\sigma=5 \times 10^{-6} \mathrm{~J} \mathrm{~m}^{-2}$ [a) and c)] and $\sigma=1 \times 10^{-5} \mathrm{~J} \mathrm{~m}^{-2}$ [b) and d)]; other conditions are the same as those of Figure 13.

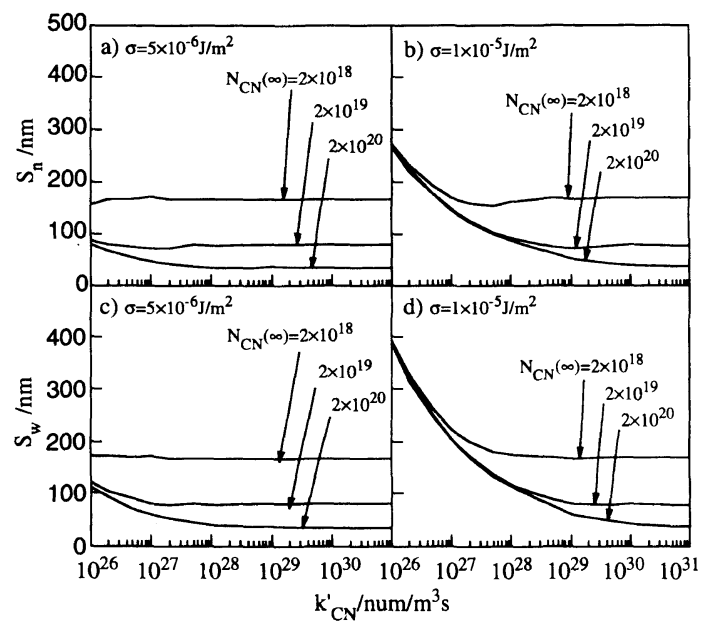

Figure 16. Relations between the number- (or weight-) average radius of the primary particle $S_{n}$. [a) and b)] (or $S_{w}$ (c and d)) [i.e., the radius of particles at the time for attainment of phase equilibrium, $t=t_{\mathrm{p}}$ ] and rate constant of nucleation $k_{\mathrm{CN}}^{\prime}$ for various limiting nuclei density $N_{\mathrm{CN}}(\infty)$ of polystyrene/cyclohexane system: $\sigma=5 \times 10^{-6}$ $\mathrm{J} \mathrm{m}^{-2}[\mathrm{a})$ and c)] and $\sigma=1 \times 10^{-5} \mathrm{~J} \mathrm{~m}^{-2}[\mathrm{~b}$ ) and d) $]$; other conditions are the same as those of Figure 13.

proceeds by diffusional growth of nuclei.

Figure 16 shows the effect of $N_{\mathrm{CN}}(\infty)$ on the relations between the number-average or the

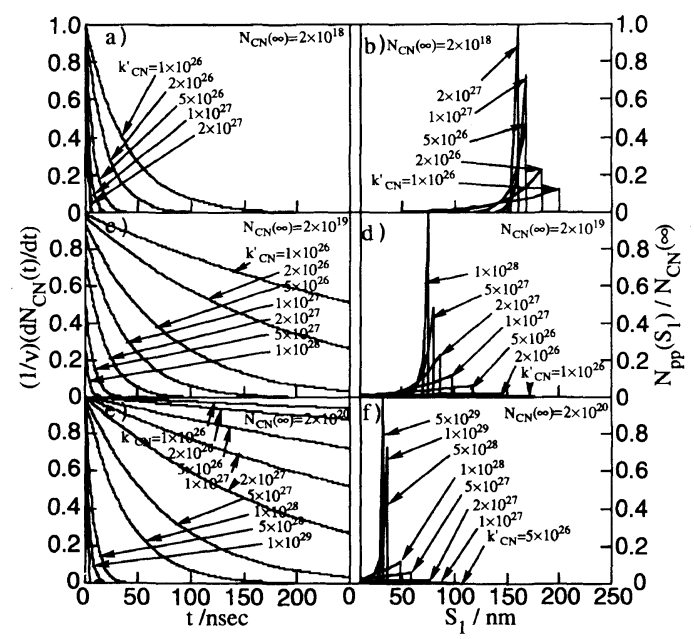

Figure 17. Plots of $(1 / v) \mathrm{d} N_{\mathrm{CN}} / \mathrm{d} t$ (eq 37$)$ as a function of time $[\mathrm{a}), \mathrm{c})$, and e)] and normalized size distribution of primary particle per unit volume at the time of attainment of equilibrium $\left.t=t_{\mathrm{P}}[\mathrm{b}), \mathrm{d}\right)$, and f)], $N_{\mathrm{PP}}\left(S_{1}\right) / N_{\mathrm{CN}}(\infty)$ for various rate constants $k_{\mathrm{CN}}^{\prime}$ (number $\mathrm{m}^{-3} \mathrm{~s}^{-1}$ ) of polystyrene/cyclohexane system: $\sigma=5 \times 10^{-6} \mathrm{~J} \mathrm{~m}^{-2}$; a) and b), $N_{\mathrm{CN}}(\infty)=2 \times 10^{18}$ number $\mathrm{m}^{-3}$; c) and d), $N_{\mathrm{CN}}(\infty)=2 \times$ $10^{19}$ number $\mathrm{m}^{-3}$ and e) and f), $N_{\mathrm{CN}}(\infty)=2 \times 10^{20}$ number $\mathrm{m}^{-2} ; v=2.971 \times 10^{25}$ number $\mathrm{m}^{-3} \mathrm{~s}^{-1}\left(k_{\mathrm{CN}}^{\prime}=1 \times 10^{26}\right)$, $v=5.942 \times 10^{25} \quad\left(k_{\mathrm{CN}}^{\prime}=2 \times 10^{26}\right), \quad v=1.486 \times 10^{26} \quad\left(k_{\mathrm{CN}}^{\prime}=\right.$ $\left.5 \times 10^{26}\right), v=2.971 \times 10^{26}\left(k_{\mathrm{CN}}^{\prime}=1 \times 10^{27}\right), v=5.942 \times 10^{26}$ $\left(k_{\mathrm{CN}}^{\prime}=2 \times 10^{27}\right), \quad v=1.486 \times 10^{27} \quad\left(k_{\mathrm{CN}}^{\prime}=5 \times 10^{27}\right)$, $v=2.971 \times 10^{27}\left(k_{\mathrm{CN}}^{\prime}=1 \times 10^{28}\right), \quad v=1.486 \times 10^{28} \quad\left(k_{\mathrm{CN}}^{\prime}=\right.$ $\left.5 \times 10^{28}\right), v=1.486 \times 10^{29}\left(k_{\mathrm{CN}}^{\prime}=5 \times 10^{29}\right)$, other conditions are the same as those of Figure 13.

weight-average radius of primary particles (i.e., the particles at $\left.t_{\mathrm{p}}\right) S_{n}$ or $S_{w}$ and $k_{\mathrm{CN}}^{\prime}$. Here, $S_{n}$ and $S_{w}$ are calculated through use of the relations,

$$
\begin{gathered}
S_{n}\left(\equiv \bar{S}_{1}\right)=\frac{\int_{0}^{\infty} S_{1} N_{\mathrm{PP}}\left(S_{1}\right) \mathrm{d} S_{1}}{\int_{0}^{\infty} N_{\mathrm{PP}}\left(S_{1}\right) \mathrm{d} S_{1}}, \\
S_{w}=\frac{\int_{0}^{\infty} S_{1}^{2} N_{\mathrm{PP}}\left(S_{1}\right) \mathrm{d} S_{1}}{\int_{0}^{\infty} S_{1} N_{\mathrm{PP}}\left(S_{1}\right) \mathrm{d} S_{1}},
\end{gathered}
$$

where $N_{\mathrm{PP}}\left(S_{1}\right)$ (number $\mathrm{m}^{-4}$ ) is the primary particle radius $\left(=S_{1}\right)$ distribution. Particle size distribution $N_{\mathrm{CN}}\left(S_{\mathrm{N}}(t-\tau), t\right)$ at time $t(0<\tau<t)$ 


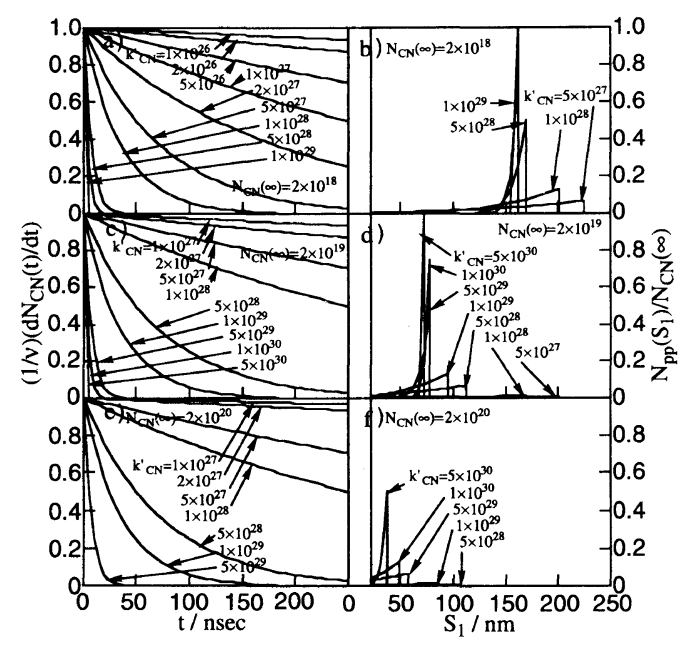

Figure 18. Plots of $(1 / v) \mathrm{d} N_{\mathrm{CN}} / \mathrm{d} t$ (eq 37) as a function of time [a), c), and e)] and normalized distribution of primary particle per unit volume at $\left.t=t_{\mathrm{P}}[\mathrm{b}), \mathrm{d}\right)$, and f)], $N_{\mathrm{PP}}\left(S_{1}\right) / N_{\mathrm{CN}}(\infty)$ for various rate constant $k_{\mathrm{CN}}^{\prime}$ (number $\left.\mathrm{m}^{-3} \mathrm{~s}^{-1}\right)$ of polystyrene/cyclohexane system: $\sigma=1 \times 10^{-5}$ $\mathrm{J} \mathrm{m}^{-2}$ assumed; other conditions are the same as those of Figure 17.

is given by the following equation,

$$
\begin{gathered}
N_{\mathrm{CN}}\left(S_{\mathrm{N}}(t-\tau), t\right)=v \exp \left(-\frac{v}{N_{\mathrm{CN}}(\infty)} \tau\right) \\
0<\tau<t .
\end{gathered}
$$

Note that $S_{\mathrm{N}}(t-\tau)$ satisfies eq 27. At $t=t_{\mathrm{P}}$, $N_{\mathrm{CN}}\left(S_{\mathrm{N}}(t-\tau), t\right)$ coincides with $N_{\mathrm{PP}}\left(S_{1}\right)$. With an increase in $k_{\mathrm{CN}}^{\prime}$ both $S_{n}$ and $S_{w}$ approach their asymptotic values, which strongly depend on $N_{\mathrm{CN}}(\infty)$. This means explicitly that $S_{n}$ and $S_{w}$ are mainly governed by $N_{\mathrm{CN}}(\infty)$, rather than by $k_{\mathrm{CN}}^{\prime}$ for larger $k_{\mathrm{CN}}^{\prime}$.

Figures $17 \mathrm{a}, 17 \mathrm{c}$, and $17 \mathrm{e}\left(\sigma=5 \times 10^{-6}\right.$ $\left.\mathrm{J} \mathrm{m}^{-2}\right)$ and Figures 18a, 18c, and $18 \mathrm{e}$ $\left(\sigma=1 \times 10^{-5} \mathrm{~J} \mathrm{~m}^{-2}\right)$ show change in $(1 / v) \mathrm{d} N_{\mathrm{CN}} /$ $\mathrm{d} t$ (see, eq 37) with time for various combinations of $N_{\mathrm{CN}}(\infty)$ and $k_{\mathrm{CN}}^{\prime}$. In the figure, $t_{\mathrm{P}}$ is indicated as an unfilled circle and $(1 / v) \mathrm{d} N / \mathrm{d} t$ becomes zero beyond $t_{\mathrm{p} .}(1 / v) \mathrm{d} N_{\mathrm{CN}} /$ $\mathrm{d} t$ decreases more rapidly with time for larger $N_{\mathrm{CN}}(\infty)$ and larger $k_{\mathrm{CN}}^{\prime}$.

Figures $17 \mathrm{~b}, 17 \mathrm{~d}$, and $17 \mathrm{f}\left(\sigma=5 \times 10^{-6}\right.$ $\left.\mathrm{J} \mathrm{m}^{-2}\right)$ and Figures $18 \mathrm{~b}, 18 \mathrm{~d}$, and $18 \mathrm{f}(\sigma=$
$1 \times 10^{-5} \mathrm{~J} \mathrm{~m}^{-2}$ ) show normalized size distribution of the primary particles (i.e., $t=t_{\mathrm{P}}$ ), $N_{\mathrm{PP}}\left(S_{1}\right) / N_{\mathrm{CN}}(\infty)$. The mean particle size shifts to smaller $S_{1}$ side with an increase in $N_{\mathrm{CN}}(\infty)$. Extremely sharp distribution of the primary particles is obtained for larger $k_{\mathrm{CN}}^{\prime}$, in other words, the primary particles are uniform in size. Lower $k_{\mathrm{CN}}^{\prime}$ yields very broad size distribution of the primary particles, especially for larger $\sigma$ value (in this case $\sigma=1 \times 10^{-5}$ $\mathrm{Jm}^{-2}$ ).

\section{CONCLUSIONS}

There are at the initial stage two elementary steps: The nucleation and growth of nuclei by diffusion, which occur concurrently until $t=t_{\mathrm{p}}$. The following conclusions are obtained.

(1) $S_{\mathrm{CN}}$ is determined by both $\sigma$ and $\Delta f_{v}$ (eq 15).

(2) Growth rate of nucleus is proportional to $v_{\mathrm{p}}^{0}-v_{\mathrm{p}(1)}$ and $1 / v_{\mathrm{p}(2)}$, respectively (eq 28 ).

(3) Integral equation which determine $t_{\mathrm{P}}$ is suggested (eq 39) and $t_{\mathrm{P}}$ is in the order of $50-500 \mathrm{~ns}$.

(4) Primary particles (PP) are rigorously defined as the nuclei at $t=t_{\mathrm{P}}$ and are proved to be different each other in size depending on the time of nucleation.

(5) The method to calculate distribution of radius of PP, $N_{\mathrm{PP}}\left(S_{1}\right)$ is established (eq 42) and $N_{\mathrm{PP}}\left(S_{1}\right)$ becomes sharp with the increase of $k_{\mathrm{CN}}^{\prime}$ and with the decrease of $N_{\mathrm{CN}}(\infty)$ and $\sigma$.

In this article, an isothermal process was treated, but this treatment can readily be generalized to any non-isothermal process.

\section{GLOSSARY OF SYMBOLS}

$D=$ diffusion coefficient

$M=$ molecular weight of polymer

$N_{\mathrm{A}}=$ Avogadro's constant

$N_{\mathrm{CN}}=$ number of critical nuclei per unit volume (number $\mathrm{m}^{-3}$ )

$N_{\mathrm{CN}}(t)=N_{\mathrm{CN}}$ at $t$

$N_{\mathrm{CN}}(\infty)=N_{\mathrm{CN}}$ at $t=\infty$ 
$N_{\mathrm{PP}}\left(S_{1}\right)=$ primary particle radius distribution

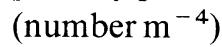

$R=$ phase volume ratio

$\tilde{R}=$ gas constant

$S_{0}=$ radius of local equilibrium region

$S_{0}(t)=S_{0}$ at $t$

$S_{1}=$ radius of primary particle

$S_{2}=$ radius of secondary particle

$S_{\mathrm{CN}}=$ radius of critical nucleus

$S_{\mathrm{N}}=$ radius of nucleus

$S_{\mathrm{N}}(t)=S_{\mathrm{N}}$ at $t$

$S_{n}=$ number average of $S_{1}$

$S_{w}=$ weight average of $S_{1}$

$T=$ Kelvin temperature

$T_{\mathrm{CP}}=$ cloud point temperature

$T_{\mathrm{P}}=$ phase separation temperature

$V_{0}=$ molar volume of solvent

$V_{0}(t)=$ total volume of $S_{0}$ spheres including growing particles at $t$

$V_{(1)}=$ volume of polymer-rich phase

$V_{(2)}=$ volume of polymer-lean phase

$X=$ degree of polymerization of polymer

$d_{\mathrm{PL}}=$ density of polymer

$k_{\mathrm{B}}=$ Boltzman constant

$k_{\mathrm{CN}}=$ rate constant (number $\mathrm{m}^{-3} \mathrm{~s}^{-1}$ )

$k_{\mathrm{CN}}^{\prime}=$ rate constant of nucleation

$p_{1}=1$ st order concentration-dependence parameters of $\chi$

$p_{2}=2$ nd order concentration-dependence parameters of $\chi$

$t=$ growing time of nucleus by diffusion

$t_{\mathrm{P}}=$ time at which the phase separation of the whole system is attained

$t_{i}=i \Delta t$

$v_{0}^{0}=$ initial concentration of solvent

$v_{0(1)}=$ volume fraction of solvent of polymer-lean phase

$v_{0(2)}=$ volume fraction of solvent of polymer-rich phase

$v_{\mathrm{p}}^{0}=$ initial (overall) polymer concentration

$v_{\mathrm{p}}^{\mathrm{c}}=$ polymer volume fraction of critical solution point

$v_{\mathrm{p}}^{\mathrm{s}}=$ polymer volume fraction of the starting solution

$v_{X}^{0}=$ initial polymer concentration

$v_{X}^{\mathrm{c}}=$ critical polymer volume fraction

$v_{X(1)}=$ polymer volume fraction of $X$-mer of polymer-lean phase in equilibrium

$v_{X(2)}=$ polymer volume fraction of $X$-mer of polymer-rich phase in equilibrium

$v_{X(1)}^{\mathrm{SP}}=$ spinodal concentration of $X$-mer of polymer-lean phase side

$v_{X(2)}^{\mathrm{SP}}=$ spinodal concentration of $X$-mer of polymer-rich phase side

$w_{X}=$ weight fraction of $X$-mer

$\Delta G_{v}=$ Gibbs' free energy change of mixing per unit volume

$\Delta G_{\mathrm{v}}\left(v_{X}^{0}\right)=\Delta G_{v}$ at $v_{X}^{0}$

$\Delta \bar{G}\left(v_{X}^{0}\right)=$ average Gibbs' free energy of coexisting phases $\mathrm{A}$ and $\mathrm{B}$

$\Delta V_{\mathrm{p}(1)}\left(t_{i}\right)=$ increment of polymer volume in the polymer-lean phase during $t=t_{i-1}$ and $t=t_{i}$ (given by eq 25)

$\Delta V_{p(2)}\left(t_{i}\right)=$ increment of polymer volume in the polymer-rich phase during $t=t_{i-1}$ and $t=t_{i}$ (given by eq 26)

$\Delta f_{v}=$ free energy change of coagulation per unit volume

$\Delta t=$ hypothetical time interval of diffusion $\left(=t_{i}-t_{i-1}\right)$

$\Delta \phi(S)=$ activation energy of formation of a nucleus with the radius $S$

$\Delta \phi_{\mathrm{CN}}=$ activation energy of formation of critical nucleus

$\Delta \mu_{0}=$ chemical potential of solvent

$\Delta \mu_{X}=$ chemical potential of $X$-mer

$\chi=$ thermodynamic interaction parameter between solvent and polymer

$\chi_{0}=$ at infinite dilution

$\phi(x)=$ error function

$v=$ rate constant of nucleation

$\left[=k_{\mathrm{CN}}^{\prime} \exp \left(-\frac{\Delta \phi_{\mathrm{CN}}}{k_{\mathrm{B}} T}\right)\right]$

$\theta=$ theta temperature

$\sigma=$ interfacial energy between the nu- 
cleus and its surrounding $\tau=$ time of formation of nucleus $\psi_{0}=$ entropy parameter

\section{REFERENCES}

1. R. L. Riley, J. O. Gardner, and U. Merten, Science, 143, 801 (1964).

2. R. D. Schultz and S. K. Asunmaa, "Recent Progress in Surface Science," Vol. 3, J. F. Danielli, A. C. Riddiford, and M. Rosenberg, Ed., Academic Press, New York, N.Y., 1970, pp 291-332.

3. R. E. Kesting and A. Manefee, Kolloid Z., 230, 241 (1969).

4. C. A. Smolders, "Ultrafiltration Membranes and Applications,” A. R. Cooper, Ed., Plenum Press, New York, N.Y., 1980, p 161.

5. W. Pusch and A. Walch, J. Membrane Sci., 10, 325 (1982).

6. K. Kamide, S. Manabe, T. Matsui, T. Sakamoto, and S. Kajita, Koubunshi Ronbunshu, 34, 205 (1977).

7. K. Kamide and S. Manabe, "Material Science of Synthetic Membranes," ACS Symposium Series, No. 269, D. R. Lloyd, Ed., American Chemical Society, Washington, D.C., 1985, pp 197-228.

8. S. Manabe, Y. Kamata, H. Iijima, and K. Kamide, Polym. J., 19, 391 (1987).

9. See, for example, J. W. Cahn, J. Chem. Phys., 42, 93 (1965).

10. K. Kamide, S. Matsuda, T. Dobashi, and M. Kaneko, Polym. J., 16, 839 (1984).

11. K. Kamide and S. Matsuda, Polym. J., 16, 825 (1984).

12. K. Kamide, S. Matsuda, and M. Saito, Polym. J., 17, 1013 (1985).

13. S. Matsuda, Polym. J., 18, 981 (1986).

14. See, for example, L. Manderkern, "Crystallization of Polymers," McGraw-Hill Book Co., 1964, Chapter 8.

15. See, for example, H. Margenau and G. M. Murphy, "The Mathematics of Physics and Chemistry," D. Van Nostrand Co., 1943, Chapter 7.

16. M. Heinrich and B. A. Wolf, Polymer, 33, 1926 (1992). 